\title{
Assessment of the anti-diabetic effect of Bauhinia variegata gold nano-extract against streptozotocin induced diabetes mellitus in rats
}

\author{
Abeer Hamed Abdel-Halim ${ }^{1 *}$, Amal Abdel Azeem Fyiad ${ }^{1}$, Wael Mahmoud Aboulthana ${ }^{1}$, Nermin Mohammed El-Sammad ${ }^{1}$, \\ Ahmed Mahmoud Youssef ${ }^{2}$, Mamdouh Moawad Ali ${ }^{1}$ \\ ${ }^{1}$ Biochemistry Department, Genetic Engineering and Biotechnology Division, National Research Centre, 33 Bohouth St., P.O. 12622, Dokki, Giza, Egypt. \\ ${ }^{2}$ Packaging Materials Department, Chemical Industries Research Division, National Research Centre, Dokki, Giza, Egypt.
}

\begin{tabular}{l}
\hline ARTICLE INFO \\
\hline Received on: 04/10/2019 \\
Accepted on: 18/02/2020 \\
Available online: 06/05/2020
\end{tabular}

Key words:

Diabetes mellitus, Bauhinea variegata, streptozotocin, nanotechnology.

\begin{abstract}
Diabetes mellitus (DM) is the most common type of the metabolic endocrine disorders. It is categorized as the third cause of death after heart and cancer diseases. Due to the undesirable side effects of the synthetic anti-diabetic drugs, the medicinal plants were selected for DM treatment. The recent studies directed to use nanotechnology in medicine to overcome restrictions of the drugs that were represented by weak bioavailability, insolubility in water, low absorption by the intestine, and inability to reach to the appropriate site of action. The study aimed to investigate the antioxidant, antidiabetic, and hypolipidemic effect of Bauhinia variegata (B. variegata) extract before and after incorporating gold nanoparticles (Au-NPs) against DM induced by streptozotocin (STZ) in rats. The present study conducted on 36 male albino Western rats divided into six groups \{control, B. variegata extract treated group, B. variegata gold nano-extract treated group, diabetic group [injected by STZ intrapretinoally (i.p.) at a dose of $60 \mathrm{mg} / \mathrm{kg}$ ], diabetic rats treated with $B$. variegata extract, and $B$. variegata gold nano-extract groups $\}$. The DM related biochemical functions (liver and kidney functions, glucose, insulin, and lipid profile) were assayed. Moreover, the enzymatic and non-enzymatic antioxidants were assayed in addition to lipid peroxidation products in liver and pancreas. Furthermore, the native protein, lipoprotein patterns, and isoenzymes were electrophoretically studied. It was found that the administration of both B. variegata extract and nano-extract to diabetic rats ameliorated the deleterious effects that occurred as a result of STZ injection and restored the biochemical functions in addition to levels of hepatic and pancreatic antioxidants to normalcy. These findings were supported by the histopathological examination. It was concluded that B. variegata nano-extract exhibited more antidiabetic effect through restoring the normal architecture of pancreatic $\beta$-cells in addition to the antioxidant and hypolipidemic effect than extract alone, which indicated that the efficacy of B. variegata extract was increased after the incorporation of Au-NPs.
\end{abstract}

\section{INTRODUCTION}

Diabetes Mellitus (DM) belongs to the metabolic disorders that are characterized by disrupting metabolism of proteins, carbohydrates, and fats with an increase in blood glucose levels. Subsequently, it leads to damage of different organs, including heart, kidneys, and eyes (Surya et al., 2014; Kulkarni and Garud, 2016; Aboulthana et al., 2018).

\section{"Corresponding Author}

Abeer Hamed Abdel-Halim, Department of Biochemistry, National Research Centre,Dokki 12622,Egypt.E-mail: abeer.hamed@yahoo.com
Two types of DM were well known. Type I is insulin dependent and occurred as a result of either partial or complete insufficient insulin secretion. Type II diabetes is called insulin resistance and characterized by low sensitivity of tissue to insulin. About $90 \%$ of DM patients are suffering from Type II diabetes and therefore, it is considered as the commonest form of diabetes (Kumar et al., 2015; Kulkarni and Garud, 2015). It represents the third reason for death, following the heart and cancer diseases (Guariguata, 2011). The number of diabetic patients was about 382 million in 2013 and predicted to increase to 592 million by 2035 (Sheweita et al., 2016).

Streptozotocin (STZ) is a naturally occurring nitrosourea product synthesized by a strain of the soil microbe Streptomyces 
achromogenes (Vivek, 2010). It is an unusual aminoglycoside containing a nitrosoamino group that enables the metabolite to act as a nitric oxide donor. It is widely used to induce permanent diabetes in rats due to its ability to destroy $\beta$ cells and insulinsecreting pancreatic endocrine cells directly (Kumar et al., 2015). Current use of STZ is mostly as an investigational drug for diabetes research (Ali and Agha, 2009). It induces hyperglycemia during 72 hours associated with various side effects as injury of liver and kidney tissues associated with bone marrow depression (Brenna et al., 2003; Akbarzadeh, 2007).

Several studies suggested recently that free radicals play a key role in the pathogenesis of diabetes. Therefore, drugs that have antioxidant capacity could be effective in reducing diabetic complications as antipathies, cardiovascular disorders, blindness, renal failure, neuropathies, and cancers (Roy et al., 2011; Sheweita et al., 2016). The available synthetic drugs for DM are cost effective and associated with different side effects, hence searching for alternative drugs that can overcome these problems, is considered as a persistent need (Balde et al., 2015). Plants were and still an important source for antidiabetic drugs where they deal with our bodies without side effects (Gandhi and Sasikumar, 2012). Bauhinia variegata L. (B. variegata) (also known as orchid tree, camel's foot tree, mountain ebony, or Kanchnar) is one of these plants that used in traditional medicine, especially in India. It belongs to the family Fabaceae. They have different biological activities, including anti-inflammatory, antimicrobial, anti-diabetic, antitumor, analgesic, astringent, and diuretic effects (Rashid, 2014; Kulkarni and Garud, 2015). Different parts of B. variegata are rich in active phyto-constituents as glycosides, flavonoids, steroids, and terpenes, which exhibit high biological activities.

It was reported that $B$. variegata leaves contain isoquercetin, quercetin 3-methyl ether, naringenin, rutin, and luteolin (Kulkarni and Garud, 2016). In addition, ethanolic $B$. variegata leaves extract is rich in insulin like protein, which has a partial identical amino acid sequence to the bovine insulin that exhibit an effective role in lowering level of blood glucose (Rashid, 2014).

Most of these biologically active components absorbed slowly due to their high molecular weights that decrease their ability to cross the cellular lipid membrane and subsequently lead to decrease in their efficacy and bioavailability. Therefore, the integration of the traditional medicinal plants with nanotechnology can overcome such problems where it can increase their bioavailability, avoid repeated administration, and reduce their toxicity. So that, the drugs at the nano-scale can achieve this purpose for increasing the activity and therapeutic effect of extracts (Prasad, 2014; Bonifácio et al., 2014; Mamillapalli et al., 2016). From this point of view, this study was designed to select the most effective plant extract to be incorporated by gold nanoparticles (Au-NPs), and hence to investigate its antioxidant, anti-diabetic, and hypolipidemic effect against STZ-induced DM in rats.

\section{MATERIALS AND METHODS}

\section{Chemicals}

STZ, Commassie Brilliant Blue G-250, Sudan Black B (SBB), Fast Blue RR, and all other chemicals were procured from Sigma-Aldrich (St. Louis, MO).

\section{Preparation of plant extract}

Young B. variegata L. (var. Candida) leaves were freshly collected from Orman garden then dried in an incubator at $50^{\circ} \mathrm{C}$ for 72 hours. The dried leaves were consequently crushed into powdered materials using an electric blender then percolated with different solvents (methanol, ethanol, water, and ethyl acetate) according to the protocol documented by Gaber and Elsayed (2010) at room temperature for 3 days. The residues were obtained through evaporating the different extracts in oven at $37-40^{\circ} \mathrm{C}$.

\section{Determination of total polyphenols and antioxidant activity}

The biological efficiency was evaluated through quantifying the total polyphenolic compounds (Singleton and Rossi, 1965), total antioxidant capacity (Prieto et al., 1999), and total reducing power (Oyaizu, 1986) in addition to percentage of the antioxidant activity that was assayed using 2,2-diphenyl-1picryl-hydrazyl-hydrate (DPPH) as free radicals initiator (BrandWilliams et al., 1995) in the different plant extracts to select the most suitable and effective one.

\section{Synthesis of gold nanoparticles (Au-NPs)}

The Au-NPs was commonly fabricated by the chemical reduction method through two main parts. The first part was carried out by reduction of $\mathrm{Au}^{+3}\left(\mathrm{HAuCl}_{4}\right)$ to $\mathrm{Au}^{0}$ through the reaction between tetrachloroauric acid $(\mathrm{HAuCl})$ and trisodium citrate $\left(\mathrm{Na}_{3} \mathrm{C}_{6} \mathrm{H}_{5} \mathrm{O}_{7} \cdot 2 \mathrm{H}_{2} \mathrm{O}\right)$ in an aqueous solution. The second part was carried out to avoid the particles aggregation by stimulating the stabilization using cetyltrimethylammonium bromide (CTAB) (Zhao et al., 2013). Finally, the Au-NPs with narrow size distribution were synthesized and Zeta sizer, transmission electron microscopy (TEM) and x-ray diffraction pattern (XRD) were used to characterize and determine the size and size distribution of the synthesized gold nanoparticles.

\section{Preparation of cellulose nanocrystal (CNC)}

Alkali solution $(4 \% \mathrm{~W} / \mathrm{V} \mathrm{NaOH})$ was added to round bottom flask containing a desired amount of dried rice straw powder under reflux condition at $100-120^{\circ} \mathrm{C}$ for 2 hours. After the filtration of the mixture, it was washed several times with distilled water to remove hemicellulose and lignin dissolved in the solution. The resulting fiber was dried to be used for the bleaching treatment that was performed by adding desired weight $(30 \mathrm{~g})$ of the dried fiber into $200 \mathrm{ml}$ of solution consisting of $\mathrm{NaClO}_{2}(1.7 \%)$, acetic buffer and distilled water under reflux condition at $110-130^{\circ} \mathrm{C}$ for 4 hours. The mixture was filtered after cooling then washed with distilled water for obtaining the white cellulose that was consequently dried at $-39^{\circ} \mathrm{C}$ for 24 hours using freeze dryer (Labconco). CNC was prepared by adding approximately $5 \%$ of cellulose fiber to sulfuric acid solution (65-wt. $\% \mathrm{H}_{2} \mathrm{SO}_{4}$ ) under fixed time and temperature conditions at $45^{\circ} \mathrm{C}$ for 45 minutes for achieving optimum yield. After sulfuric acid hydrolysis, the hydrolyzed cellulose was washed five times by centrifuging the solution at $10,000 \mathrm{rpm}$ for 10 minutes for removing the excess sulfuric acid. The resulting suspension of $\mathrm{CNC}$ was dialyzed against distilled water until achieving constant $\mathrm{pH}$. The resultant $\mathrm{CNC}$ suspension was stored in refrigerator until to be used. 


\section{Preparation of $B$. variegata gold nano-extract}

Bauhinia variegata nano-emulsion was prepared using B. variegata crude ethanol extract, non-ionic surfactant Tween 20 (HLB-16.7), CNC, and water via spontaneous emulsification method. Nano-emulsion was carried out in two steps: in the first step, organic phase was fabricated through mixing $B$. variegata crude sample with chosen surfactant (Tween20) in the following ratio (1:5). This was followed by adding $3 \mathrm{~g}$ of $\mathrm{CNC}$ to the mixture that was consequently sonicated for 30 minutes. In the second stage, the organic phase (B. variegata, Tween 20 and CNC) was added drop-by-drop $(20 \mathrm{ml} / \mathrm{min})$ to water using separating fennel and stirring the system magnetically $(800 \mathrm{rpm})$ at $60^{\circ} \mathrm{C}$ for 5 hours. Then, the prepared gold nanoparticles (Au-NPs) were added to the prepared nano-emulsion by the following ratio (1\%). The mixture was sonicated to another 30 minutes at $50^{\circ} \mathrm{C}$.

\section{Characterization of the prepared Au-NPs}

$X R D$

Crystal structure of the synthesized Au-NPs was determined by a Philips X-ray diffractometer (PW 1930 generator, $\mathrm{PW} 1820$ goniometer) that equipped with $\mathrm{Cu} \mathrm{K} \alpha$ radiation $(45 \mathrm{kV}$, $40 \mathrm{~mA}$, with $\lambda=0.15418 \mathrm{~nm})$. The analysis scans were run in $2 \theta$ range of $5-80^{\circ}$ with 0.02 step size and 1 second step time.

TEM

The synthesized Au-NPs were characterized morphologically in addition to determining the particles size by using TEM (JEM-1230, Japan) operated at $120 \mathrm{kV}$ with resolution until $0.2 \mathrm{~nm}$ and maximum magnification of $600 \times 10^{3}$. Before characterization, aqueous sample dispersion (one drop) was placed on a carbon-coated copper grid then allowed in air to dry.

\section{Median lethal dose of $B$. variegata extract and nano-extract $\left(\mathbf{L D}_{50}\right)$}

The ethanolic B. variegata extracts (before and after incorporating $\mathrm{Au}-\mathrm{NPs}$ ) were evaluated for calculating the $\mathrm{LD}_{50}$. One hundred and twelve adult albino Western rats (weighting 150-180 g) were used. They divided into two sets of seven groups (eight rats/group) for evaluating the $\mathrm{LD}_{50}$ of both $B$. variegata extract and nano-extract. Mortality was recorded after 24 hours of oral administration of extract and nano-extract with rising doses $(10,20,30,40,50,60$, and $70 \mathrm{ml} / \mathrm{kg})$. The $\mathrm{LD}_{50}$ was calculated according to the equation suggested by Paget and Barnes (1964). It was found that the $\mathrm{LD}_{50}$ values of the $B$. variegata extract and gold nano-extract were found to be 36.50 and $51.5 \mathrm{ml} / \mathrm{kg}$. Therefore, the doses used for the therapeutic investigation were determined as $1 / 20 \mathrm{LD}_{50}$ for the extract and nano-extract $(1.83$ and $2.58 \mathrm{ml} /$ $\mathrm{kg}$, respectively).

\section{Animals}

Thirty-six healthy male albino Western rats (weighting 150-180 g) were housed for 7 days in our laboratory in National Research Centre, Dokki, Giza, Egypt, where they maintained under normal nutritional and environmental conditions (12 hours light/dark cycles and $25 \pm 2{ }^{\circ} \mathrm{C}$ ). The experimental protocols for the studying and handling of animals were performed according to the Institutional Animal Ethical Committee of National Research Centre (No: 19070) and was conducted in accordance with "Guide for the care and use of laboratory animal."

\section{Induction of diabetes mellitus}

Rats were fasted overnight and injected intraperitoneally (i.p.) by single dose of freshly prepared STZ solution in citrate buffer $(100 \mathrm{mM} / \mathrm{l}$ at $\mathrm{pH} 4.5)$ at a dose of $60 \mathrm{mg} / \mathrm{kg}$ b.w. (Archana et al., 2001). After 72 hours of STZ administration, the blood was collected from tail vein for estimating fasting blood glucose level using Accu-Chek sensor (comfort glucometer (China). Rats were considered as diabetic when blood glucose level exceeded 250 $\mathrm{mg} / \mathrm{dl}$.

\section{Experimental design}

Animals were housed in six cages (six rats per cage) and randomly divided as following:

- Control group: Rats were fed with normal diet and received tap water.

- Bauhinia variegata extract treated (E) group: Rats were orally treated with ethanolic $B$. variegata extract at a dose of $1.83 \mathrm{ml} / \mathrm{kg}\left(1 / 20 \mathrm{LD}_{50}\right)$.

- Bauhinia variegata gold nano-extract treated (N) group: Rats were orally treated with $B$. variegata gold nano-extract at a dose of $2.58 \mathrm{ml} / \mathrm{kg}\left(1 / 20 \mathrm{LD}_{50}\right)$.

- Diabetic (D) group: Rats were i.p. injected with a single dose of STZ and then diabetic rats were sacrificed after 1 week of STZ injection.

- Diabetic group treated with B. variegata extract (D+E): Rats i.p. injected with STZ then treated with ethanolic $B$. variegata extract at a dose of $1.83 \mathrm{ml} / \mathrm{kg}$.

- Diabetic group treated with $B$. variegata gold nano-extract $(\mathrm{D}+\mathrm{N})$ : Rats i.p. injected with STZ then treated with $B$. variegata gold nano-extract at a dose of $2.58 \mathrm{ml} / \mathrm{kg}$.

\section{Collection of samples}

At the end of the experiment (4 weeks), rats were fasted for 18 hours and anesthetized by slight exposure to diethyl ether then sacrificed by cervical dislocation. Blood samples were drawn from retro-orbital plexus and divided into two parts. Part I was deposited in $\mathrm{NaF}$ glucose vacuum tubes (Becton Dickinson, New York, NJ) for glucose estimation. Part II was allowed to clot at room temperature, centrifuged for 15 minutes at 3,000 rpm, and then serum was separated and kept in at $-20^{\circ} \mathrm{C}$ until used for the biochemical assays. After sacrificing the animals by cervical dislocation, the pancreas and liver tissues were excised and divided into three portions. A small portion was immediately preserved in $10 \%$ neutral buffered formalin solution for histopathological investigation. The second portion was homogenized in potassium phosphate buffer ( $\mathrm{pH}$ 7.4) using Tissue Master TM125 (Omni International, USA). The liver and pancreas tissue homogenates were centrifuged at $3,000 \mathrm{rpm}$ for 10 minutes, and the clear supernatant was stored at $-80^{\circ} \mathrm{C}$ to be used for biochemical assays. The last portion of liver and pancreas tissues was rapidly frozen in liquid nitrogen for electrophoretic analysis. 


\section{Biochemical analysis}

Glucose level, liver enzymes [serum Alanine Aminotransferase (ALT), Aspartate Aminotransferase (AST), Alkaline Phosphatase (ALP)], concentrations of Total Protein (TP), Kidney functions (Urea, Creatinine), as well as lipid profile [Total Cholesterol (TC), Triglycerides (TGs), and HDL-cholesterol] were assayed using commercially available kits (Spectrum Diagnostics Egyptian Company for Biotechnology, Cairo, Egypt). Moreover, LDL-cholesterol was calculated by the formula of Schumann and Klauke (2003)

$$
\mathrm{LDL}=\left[(\mathrm{TC}-\mathrm{HDL})-\frac{\mathrm{TG}}{5}\right]
$$

In addition, insulin level was quantified in plasma using sandwich enzyme-linked immuno sorbent assay (ELISA) following instruction of the kit (ELISA, Boerhringer Mannheim, Mannheim, Germany).

Reduced glutathione was estimated in hepatic and pancreatic tissues according to the method described by Beutler et al. (1963). Catalase and Superoxide Dismutase activities were evaluated in liver and pancreas according to the methods of Aebi (1984) and Minami and Yoshikawa (1979), respectively. Thiobarbituric acid reactive substances (TBARS) were estimated as a marker for lipid peroxidation in hepatic and pancreatic tissues according to method suggested by Lefevre et al. (1998).

\section{Statistical analysis}

The statistical analysis was carried out by one-way analysis of variance test followed by Bonferroni test using Statistical Package for Social Sciences (SPSS for windows, version 19.0). The results were expressed in tables and figures as mean \pm standard error (SE). The differences were considered as statistically significant when a " $p$ " value was less than 0.05 .

\section{Native electrophoretic patterns}

\section{Protein patterns}

The pancreas and liver tissues were rapidly frozen in liquid nitrogen and homogenized in Tris- $\mathrm{HCl}$ buffer $(0.01 \mathrm{M}$ and $\mathrm{pH}$ 7.4). The clear supernatants were transferred to new tubes after centrifuging the homogenates at 10,000 rpm for 15 minutes. Equal volumes of the individual supernatants in each group were mixed together in one tube and used as one sample. The concentration of TP was assayed in all samples (Bradford, 1976). During the electrophoretic assays, the samples loaded in all wells with equal protein concentrations.

Native proteins were electrophoretically separated using Polyacrylamide Gel Electrophoresis based on the methods documented by Hames (1990) and modified by Darwesh et al. (2015) who reported that samples, gels, and running buffers contained no sodium dodecyl sulfate. The native protein bands were stained by Commassie Brilliant Blue G-250 and visualized as blue bands. The lipid moieties of native protein were stained by SBB visualized as black bands (Subramaniam and Chaubal, 1990).

\section{Isoenzymes}

The isoenzymes were electrophoretically detected through the identification of the enzyme subunits. First, electrophoretic catalase pattern (CAT) and electrophoretic peroxidase (POX) pattern were assayed for native gel after electrophoretic run by incubating with $\mathrm{H}_{2} \mathrm{O}_{2}$ as the substrate then stained. The stained CAT subunits appeared as yellow bands in the gel (Siciliano and Shaw, 1976). While, the stained POX subunits appeared as brown bands in the gel (Rescigno et al., 1997). Moreover, $\alpha$-amylase was electrophoretically detected according to the method suggested by Rammesmayer and Praznik (1992) through incubation of the gel with a solution containing soluble starch followed by staining with iodine solution.

The polyacrylamide gel plates were scanned then analyzed by the Quantity One software (Version 4.6.2) that was used to determine the relative mobility $(\mathrm{Rf})$, band percent $(\mathrm{B} \%)$ and band quantity (Qty) of the bands separated electrophoretically. In addition, the similarity index (SI\%) and genetic distance (GD\%) were calculated to compare all treated groups to control group.

\section{Histopathological examination}

After sacrifice, small specimens from pancreatic and hepatic tissues were autopsied and immediately preserved in $10 \%$ neutral buffered formalin solution. The tissue specimens were washed by tap water after 24 hours and dehydrated in serial dilutions of alcohol solutions, cleared in xylene, and embedded in paraffin at $56^{\circ}$ in hot air oven for 24 hours. Paraffin bees wax tissue blocks were prepared for sectioning at 4 microns thickness by slidge microtome. The obtained tissue sections were collected on glass slides and deparaffinized then stained by hematoxylin and eosin (H\&E) stain to be examined histopathologically under light microscope according to the method suggested by Banchroft et al. (1996).

\section{RESULTS}

\section{Selection of the most effective $B$. variegata extract and integration of Au-NPs}

As revealed in Table 1, it was found that the ethanolic $B$. variegata extract was the most effective extract noticed with the highest concentration of total polyphenols $(741.28 \pm 4.82 \mathrm{mg}$

Table 1. Polyphenol concentration, total antioxidant capacity and free radical scavenging activity in different B. variegata extracts.

\begin{tabular}{lcccc}
\hline Solvent & $\begin{array}{c}\text { Polyphenol } \\
(\mathbf{m g} \text { gallic acid/100gm) }\end{array}$ & $\begin{array}{c}\text { Total antioxidant capacity } \\
(\mathbf{m g} \text { gallic/gm) }\end{array}$ & $\begin{array}{c}\text { Reducing power }(\boldsymbol{\mu g} / \mathbf{m L}) \\
\text { Antioxidant activity } \\
(\mathbf{\%})\end{array}$ \\
\hline Methanol & $729.02 \pm 3.45$ & $3.98 \pm 0.036$ & $11.93 \pm 1.51$ & $72.4 \%$ \\
Ethanol $^{*}$ & $\mathbf{7 4 1 . 2 8} \pm \mathbf{4 . 8 2}$ & $\mathbf{5 . 3 2} \pm \mathbf{0 . 1 3}$ & $\mathbf{1 2 . 9 4} \pm \mathbf{1 . 6 3}$ & $\mathbf{7 8} \%$ \\
Ethyl acetate & $722.76 \pm 4.11$ & $1.69 \pm 0.08$ & $9.31 \pm 1.20$ & $66 \%$ \\
Water & $619.90 \pm 9.50$ & $0.77 \pm 0.03$ & $9.15 \pm 1.15$ & $76 \%$ \\
\hline
\end{tabular}

Values expressed as mean \pm SE of four replicates, $*$ : The most effective extract with respect to the others. 
gallic acid/100 g), total antioxidant capacity $(5.32 \pm 0.13 \mathrm{mg}$ gallic $\mathrm{acid} / \mathrm{g})$, iron reducing power $(12.94 \pm 1.63 \mu \mathrm{g} / \mathrm{mL})$, and free radical scavenging activity $(78 \%)$.

Based on the in vitro experiments that used to measure the antioxidative efficiency of active ingredients, the ethanolic $B$. variegata extract was selected to be incorporated by Au-NPs according to the method suggested by Elia et al. (2014). It was found that the incorporation of Au-NPs enhanced efficiency of the ethanolic $B$. variegata extract through increasing concentration of total polyphenols, total antioxidant capacity, iron reducing power, and free radical scavenging activity $(827.76 \pm 8.94 \mathrm{mg}$ gallic $\mathrm{acid} / 100 \mathrm{~g}, 8.87 \pm 0.79 \mathrm{mg}$ gallic acid $/ \mathrm{g}, 19.22 \pm 1.94 \mu \mathrm{g} / \mathrm{mL}$, and $82 \%$, respectively) as depicted in Table 2 .

\section{Studying the structural properties of prepared Au-NPs}

The XRD and TEM are the most suitable techniques used for studying structural properties of the materials synthesized at nano-scale. The prepared Au-NPs were examined through the XRD diffraction pattern. The XRD data revealed that the fabricated $\mathrm{Au}-\mathrm{NPs}$ achieved in presence of $\mathrm{AuCl}_{4}^{-}$analogous diffraction peaks are allocated to metallic $\mathrm{Au}$ phase with the greatest significant representative peaks which seem at $38^{\circ}, 43.8^{\circ}$, and $65^{\circ}$ attributed to the crystallographic planes (llll 111$),\left(\begin{array}{lll}2 & 0 & 0\end{array}\right)$, and $\left(\begin{array}{ll}2 & 2\end{array}\right.$ $0)$, respectively. The peak width of Au-NPs from crystalline plane (1 111 ), sizes of the Au crystallite were found to be approximately $15 \mathrm{~nm}$ for Au-NPs (Youssef et al., 2014).

Moreover, the morphology of the prepared Au-NPs was examined by the TEM, which determine the shape and size of gold nanoparticles. The size of Au-NPs has been examined by determining the diameter of whole particles on TEM images. The average width of gold was in the range of $15 \mathrm{~nm}$ with very little particles of higher and lower size distribution. In addition, the TEM data displayed that the Au-NPs is that greatest of the gold nanoparticles are round or spherical in shape as shown in Figure 1.

\section{Biochemical studies}

Data compiled in Table 3 revealed that the final body weight decreased by $21.8 \%$ than initial body weight in diabetic group. While, after treatment the antidiabetic rats with $B$. variegata extract and $B$. variegata gold nano-extract, the body weight was improved where; the final body weight was increased than initial body weight in both groups by $8.88 \%$ and $13.43 \%$, respectively.

As shown in Table 4, it was found that there was significantly $(p<0.000)$ elevation in glucose level associated with significant $(p<0.000)$ decline in insulin level in diabetic rats as compared to control group. While, the treatment with ethanolic B. variegata extract and gold nano-extract decreased glucose level with significant elevation in insulin level $(p<0.000)$ comparing to diabetic group. In addition, it was found that STZ caused significant $(p<0.000)$ increment in levels of TC, TG, and
LDL-c with significant $(p<0.000)$ decline in HDL-c level when compared with control group. While after the treatment with both extracts, the lipid profile was improved (Table 4).

It was found that levels of AST, ALT, ALP, urea, and creatinine were significantly $(p<0.000)$ elevated and TP level was significantly $(p<0.000)$ decreased in diabetic group (Table 5) with respect to control group. While the treatment with ethanolic $B$. variegata extract and gold nano-extract exhibited hepato- and reno-protective effect through lowering measurements of the liver and kidney functions significantly $(p<0.000)$ as compared to diabetic group.

During the current study, it was observed that levels of the enzymatic and non-enzymatic antioxidants (SOD, CAT, and $\mathrm{GSH})$ in hepatic and pancreatic tissues decreased significantly ( $p$ $<0.000)$ associated with significant $(p<0.000)$ elevation of lipid peroxidation product (TBARS) in diabetic group with respect to control group (Table 6). The treatment with either extract or gold nano-extract improved antioxidant enzymes, GSH, and decreased TBARS level in both liver and pancreas as compared to diabetic group.

\section{Native electrophoretic protein and lipoprotein patterns}

As illustrated qualitatively in Figure 2a, the native protein pattern was expressed electrophoretically in the healthy

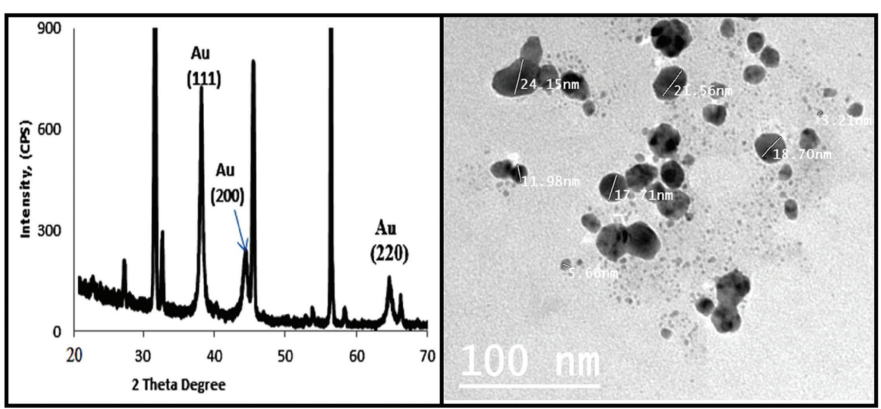

Figure 1. X-ray diffraction spectrums of Au-NPs as well as Transmission Electron Microscope image of Au-NPs.

Table 3. The effect of $B$. variegata extract before and after incorporating gold nanoparticles on initial and final body weights.

\begin{tabular}{lcc}
\hline & Initial weight $(\mathbf{g})$ & Final weight $(\mathbf{g})$ \\
\hline Control group & $200 \pm 6.95$ & $239 \pm 12.32$ \\
Extract-treated group & $186.3 \pm 2.9$ & $229.6 \pm 4.7$ \\
Nano-treated group & $197.5 \pm 5.44$ & $242.65 \pm 9.79$ \\
Diabetic group & $188.17 \pm 2.77$ & $147.28 \pm 8.46$ \\
D+E treated group & $226.7 \pm 6.15$ & $246.83 \pm 3.23$ \\
D+N treated group & $228.33 \pm 7.5$ & $259 \pm 2.66$ \\
\hline
\end{tabular}

Values were expressed as mean \pm standard error

Table 2. Polyphenol concentration, total antioxidant capacity and free radical scavenging activity in ethanolic $B$. variegata extract before and after incorporating Au-NPs.

\begin{tabular}{lcccc}
\hline Ethanol Extract & $\begin{array}{c}\text { Polyphenol } \\
(\mathbf{m g} \text { gallic acid/100gm) }\end{array}$ & $\begin{array}{c}\text { Total antioxidant capacity } \\
(\mathbf{m g} \text { gallic acid/gm) }\end{array}$ & $\begin{array}{c}\text { Reducing power } \\
(\boldsymbol{\mu g} / \mathbf{m L})\end{array}$ & $\begin{array}{c}\text { Antioxidant activity } \\
(\boldsymbol{\%})\end{array}$ \\
\hline Before & $725.44 \pm 5.72$ & $6.12 \pm 0.14$ & $14.96 \pm 1.23$ & $73 \%$ \\
After $^{*}$ & $\mathbf{8 2 7 . 7 6} \pm \mathbf{8 . 9 4}$ & $\mathbf{8 . 8 7} \pm \mathbf{0 . 7 9}$ & $\mathbf{1 9 . 2 2} \pm \mathbf{1 . 9 4}$ & $\mathbf{8 2 \%}$ \\
\hline
\end{tabular}

Values expressed as mean $\pm \mathrm{SE}$ of four replicates, *: The most effective extract in comparison to the others. 
Table 4. The effect of $B$. variegata extract before and after incorporating gold nanoparticles against STZ-induced diabetes on glucose, insulin levels and lipid profile.

\begin{tabular}{|c|c|c|c|c|c|c|c|}
\hline & & Control & Extract treated & Nano-treated & Diabetic & D+E treated & $\mathrm{D}+\mathrm{N}$ treated \\
\hline Glucose & & $99 \pm 4.7$ & $105.83 \pm 4.42$ & $95 \pm 5.39$ & $318 \pm 18.97^{\mathrm{a}}$ & $144.5 \pm 4.2^{\mathrm{ab}}$ & $127.8 \pm 1.82^{\mathrm{b}}$ \\
\hline Insulin & & $0.98 \pm 0.06$ & $1.02 \pm 0.05$ & $1 \pm 0.04$ & $0.53 \pm 0.03^{\mathrm{a}}$ & $0.75 \pm 0.02^{\mathrm{ab}}$ & $0.87 \pm 0.02^{\mathrm{b}}$ \\
\hline \multirow[t]{4}{*}{ Lipid profile } & $\begin{array}{l}\text { TC } \\
(\mathrm{mg} / \mathrm{dL})\end{array}$ & $69.96 \pm 0.81$ & $71.33 \pm 0.75$ & $68.74 \pm 1$ & $107.82 \pm 3.7^{\mathrm{a}}$ & $87 \pm 0.93^{\text {ab }}$ & $80.89 \pm 0.74^{\mathrm{ab}}$ \\
\hline & $\begin{array}{l}\text { TG } \\
(\mathrm{mg} / \mathrm{dL})\end{array}$ & $43.7 \pm 0.95$ & $43.84 \pm 1.12$ & $44.89 \pm 1.6$ & $102.54 \pm 2.68^{\mathrm{a}}$ & $61.1 \pm 0.65^{\mathrm{ab}}$ & $51.73 \pm 0.42^{\mathrm{ab}}$ \\
\hline & $\begin{array}{l}\text { HDL-c } \\
(\mathrm{mg} / \mathrm{dL})\end{array}$ & $30.97 \pm 0.8$ & $31.86 \pm 0.54$ & $32.85 \pm 0.79$ & $19.1 \pm 0.51^{\mathrm{a}}$ & $22.45 \pm 0.5^{\mathrm{ab}}$ & $28.45 \pm 0.56^{\mathrm{b}}$ \\
\hline & $\begin{array}{l}\text { LDL-c } \\
(\mathrm{mg} / \mathrm{dL})\end{array}$ & $30.25 \pm 0.8$ & $30.71 \pm 1.01$ & $28.58 \pm 0.86$ & $68.22 \pm 3.63^{\mathrm{a}}$ & $52.51 \pm 1.0^{\mathrm{ab}}$ & $41.28 \pm 0.6^{\mathrm{ab}}$ \\
\hline
\end{tabular}

Values were expressed as mean \pm standard error, $\mathbf{a}$ : significant difference from control group, $\mathbf{b}$ : significant difference from toxic group at $\mathbf{p}<0.000$.

Table 5. The effect of $B$. variegata extract before and after incorporating gold nanoparticles against STZ-induced diabetes on liver and kidney functions

\begin{tabular}{|c|c|c|c|c|c|c|c|}
\hline & & Control & Extract treated & Nano-treated & Diabetic & $\mathbf{D}+\mathbf{E}$ treated & $\mathbf{D}+\mathbf{N}$ treated \\
\hline \multirow[t]{4}{*}{ Liver functions } & $\operatorname{AST}(\mathrm{U} / \mathrm{L})$ & $34.92 \pm 1.22$ & $34.88 \pm 1.27$ & $33.95 \pm 0.73$ & $95.38 \pm 4.2^{\mathrm{a}}$ & $53.02 \pm 1.04^{\mathrm{ab}}$ & $43.12 \pm 1.1^{\mathrm{ab}}$ \\
\hline & $\operatorname{ALT}(\mathbf{U} / \mathbf{L})$ & $30.6 \pm 1.22$ & $29.1 \pm 1.93$ & $29.86 \pm 1.97$ & $79.77 \pm 2.24^{\mathrm{a}}$ & $46.39 \pm 1.34^{\mathrm{ab}}$ & $41.2 \pm 1.14^{\mathrm{ab}}$ \\
\hline & $\operatorname{ALP}(\mathbf{U} / \mathbf{L})$ & $102.24 \pm 3.85$ & $106.2 \pm 5.57$ & $105.28 \pm 2.43$ & $228.6 \pm 10^{\mathrm{a}}$ & $137.2 \pm 2.56^{\mathrm{ab}}$ & $131 \pm 2.6^{\text {ab }}$ \\
\hline & $T P(g / d L)$ & $8.77 \pm 0.41$ & $9.48 \pm 0.43$ & $9.14 \pm 0.36$ & $2.45 \pm 0.34$ & $4.92 \pm 0.26^{\mathrm{ab}}$ & $6.74 \pm 0.22^{\mathrm{ab}}$ \\
\hline \multirow[t]{2}{*}{ Kidney functions } & Urea $(\mathrm{mg} / \mathrm{dL})$ & $37.02 \pm 0.88$ & $38.19 \pm 1.51$ & $37.63 \pm 1.66$ & $120.65 \pm 7.46^{\mathrm{a}}$ & $58.5 \pm 1.5^{\mathrm{ab}}$ & $49.1 \pm 1.0^{\mathrm{b}}$ \\
\hline & Creatinine (mg/dL) & $0.21 \pm 0.03$ & $0.25 \pm 0.03$ & $0.25 \pm 0.03$ & $1.82 \pm 0.19^{\mathrm{a}}$ & $0.52 \pm 0.02^{\mathrm{b}}$ & $0.43 \pm 0.01^{\mathrm{b}}$ \\
\hline
\end{tabular}

Values were expressed as mean \pm standard error, a: significant difference from control group, $\mathbf{b}$ : significant difference from toxic group at $\mathrm{p}<0.000$.

Table 6. The effect of B. variegata extract before and after incorporating gold nanoparticles against STZ-induced diabetes on hepatic and pancreatic SOD, CAT activities, GSH and TBARS levels.

\begin{tabular}{|c|c|c|c|c|c|c|c|}
\hline & & Control & Extract treated & Nano-treated & Diabetic & D+E treated & $\mathrm{D}+\mathrm{N}$ treated \\
\hline \multirow[t]{4}{*}{ Pancreas tissue } & $\begin{array}{l}\text { SOD } \\
\text { (IU/g tissue) }\end{array}$ & $49.54 \pm 1.74$ & $52.11 \pm 1.1$ & $52.17 \pm 0.85$ & $13.1 \pm 0.81^{\mathrm{a}}$ & $34.3 \pm 0.87^{\text {ab }}$ & $40.52 \pm 0.44^{\mathrm{ab}}$ \\
\hline & $\begin{array}{l}\text { CAT } \\
\text { (IU/g tissue) }\end{array}$ & $117.23 \pm 2.1$ & $115.9 \pm 1.61$ & $115.10 \pm 1.39$ & $37.26 \pm 0.83^{\mathrm{a}}$ & $75.36 \pm 1.95^{\mathrm{ab}}$ & $92.9 \pm 1.67^{\mathrm{ab}}$ \\
\hline & $\begin{array}{l}\text { GSH } \\
\text { (mg/g tissue) }\end{array}$ & $261 \pm 22.91$ & $246.33 \pm 11.34$ & $259.8 \pm 10.87$ & $79.87 \pm 4.29^{\mathrm{a}}$ & $163.12 \pm 11.34^{\mathrm{ab}}$ & $208.3 \pm 5.1^{\mathrm{b}}$ \\
\hline & $\begin{array}{l}\text { TBARS } \\
(\mathrm{nm} / \mathrm{mL})\end{array}$ & $50.53 \pm 2.25$ & $50.1 \pm 1.65$ & $51.65 \pm 1.63$ & $184.9 \pm 4.1^{\mathrm{a}}$ & $79.1 \pm 1.17^{\mathrm{ab}}$ & $66.47 \pm 0.98^{\mathrm{ab}}$ \\
\hline \multirow[t]{4}{*}{ Liver tissue } & $\begin{array}{l}\text { SOD } \\
\text { (IU/g tissue) }\end{array}$ & $51.27 \pm 0.64$ & $49.37 \pm 0.82$ & $49.23 \pm 0.83$ & $11.57 \pm 1.07^{\mathrm{a}}$ & $35.60 \pm 0.81^{\mathrm{ab}}$ & $40.48 \pm 0.62^{\mathrm{ab}}$ \\
\hline & $\begin{array}{l}\text { CAT } \\
\text { (IU/g tissue) }\end{array}$ & $50.53 \pm 1.88$ & $48 \pm 1.77$ & $50.1 \pm 0.92$ & $7.45 \pm 0.57^{\mathrm{a}}$ & $33.98 \pm 0.7^{\text {ab }}$ & $41.75 \pm 1.0^{\mathrm{ab}}$ \\
\hline & $\begin{array}{l}\text { GSH } \\
\text { (mg/g tissue) }\end{array}$ & $233.69 \pm 5.14$ & $227.17 \pm 5.19$ & $227.67 \pm 5.03$ & $66.33 \pm 2.94^{\mathrm{a}}$ & $183.5 \pm 2.33^{\mathrm{ab}}$ & $201.7 \pm 3.65^{\mathrm{ab}}$ \\
\hline & $\begin{array}{l}\text { TBARS } \\
(\mathrm{nm} / \mathbf{m L})\end{array}$ & $38.51 \pm 1.24$ & $41.81 \pm 1.14$ & $40.52 \pm 1.55$ & $117.43 \pm 5.76^{\mathrm{a}}$ & $63.88 \pm 1.46^{\mathrm{ab}}$ & $52.83 \pm 1.1^{\mathrm{ab}}$ \\
\hline
\end{tabular}

Values were expressed as mean \pm standard error, a: significant difference from control group, $\mathbf{b}$ : significant difference from toxic group at $\mathrm{p}<0.000$.

liver tissue by seven bands and six from them are considered as common bands and identified at Rfs $0.19,0.27,0.39,0.57,0.72$, and $0.93(\mathrm{~B} \% 15.16,14.74,14.81,14.80,14.40$, and 12.42; Q\% $10.47,9.80,10.22,28.00,17.31$, and 9.52 , respectively). No electrophoretic changes noticed in livers of extract and nanoextract treated groups. In liver of diabetic group, it was found that STZ caused alterations represented by hiding the sixth band with one characteristic band was existed at Rf 0.62 (B\% 13.87 and Q\% 11.27). Therefore, the diabetic group was found with lower SI $(85.71 \%)$, and hence higher GD $(14.29 \%)$ as revealed in Figure 3. The treatment with $B$. variegata extract and nano-extract showed ameliorative effect against STZ-induced diabetes by hiding the abnormal band with re-appearing the normal one. Therefore, the SI\% and GD restored to normal values $(100 \%$ and $0 \%$, respectively). It was showed that STZ caused quantitative changes represented by the significant $(p<0.05)$ decrease in quantities of the TP bands. The treatment with the extract could not restore it to normal level. Although the nano-extract could not restore its level to normalcy, it increased the bands quantity significantly $(p<0.05)$ with respect to $\mathrm{D}$ and $\mathrm{D}+\mathrm{E}$ treated groups.

In the pancreas tissue, the native protein pattern was expressed by nine bands and two from them are considered as common bands [Rfs 0.79 and 0.96 (B\% 13.50 and 11.36; Q\% 11.96 and 13.83 , respectively)]. No electrophoretic abnormalities identified in pancreas of extract and nano-extract treated groups. In diabetic group, it was noticed absence of seven normal bands 


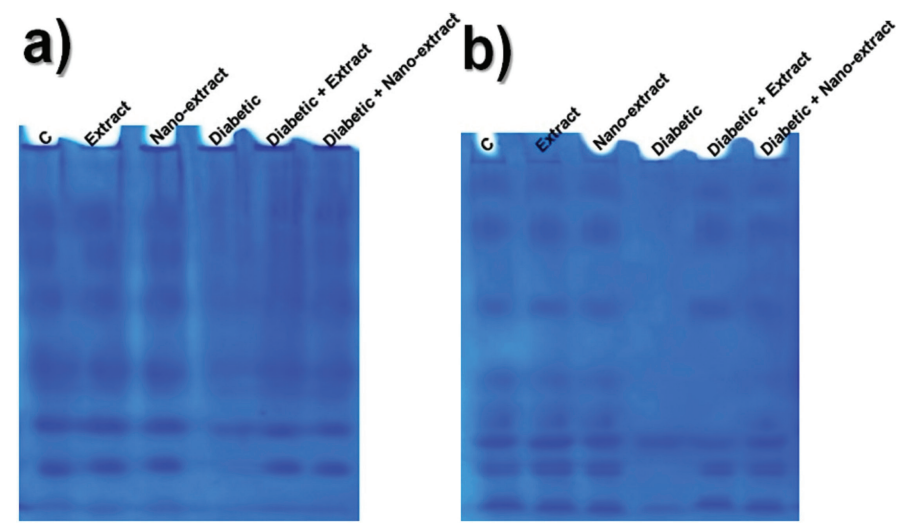

Figure 2. Electrophoretic protein patterns showing the curative effect of $B$. variegata extract before and after incorporating Au-NPs against STZ induced diabetes on (a) liver tissues and (b) pancreatic tissues of rats.

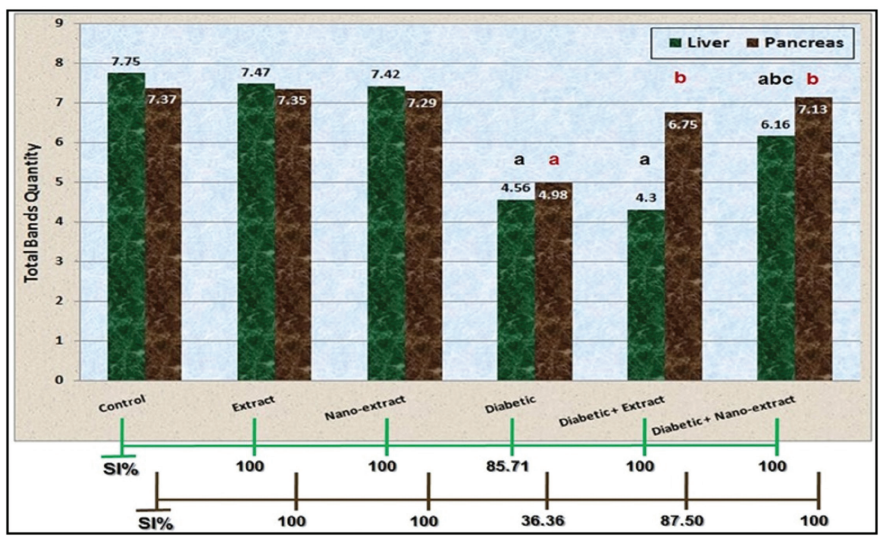

Figure 3. Data showing the ameliorative effect of $B$. variegata extract before and after incorporating Au-NPs against the quantitative and qualitative alterations induced by STZ in protein patterns in liver and pancreatic tissues of rats. Values expressed as mean $\pm \mathrm{SE}$ of three replicates, (a) significant difference at $p<0.05$ from control group, (b) significant difference at $p<0.05$ from diabetic group, (c) significant difference at $p<0.05$ from $B$. variegata extract treated group.

without appearance of abnormal ones (Fig. 2b). Therefore, the diabetic group was found with the lowest SI (36.36\%), and hence the highest GD (63.64\%) (Fig. 3). The extract restored only five normal bands (SI: $87.50 \%$ and GD: $12.50 \%$ ). While the nanoextract showed higher ameliorative effect by restoring all the normal bands (SI: 100\% and GD: 0\%). Moreover, it was found that STZ caused quantitative changes represented by the significant ( $p$ $<0.05$ ) decrease in quantities of the TP bands. The treatment with extract and nano-extract increased the bands quantity significantly $(p<0.05)$ comparing to D group.

The electrophoretic lipoprotein pattern in liver tissue of control group was represented by six bands and five from them are considered as common bands identified at Rfs 0.41, 0.59, $0.74,0.86$, and $0.96(\mathrm{~B} \% 19.35,19.56,16.58,13.33$ and 13.63; Q\% 13.42, 18.87, 21.99, 6.83 and 8.22, respectively) (Fig. 4a). No changes detected electrophoretically in livers of extract and nano-extract treated groups. It was found that STZ caused alterations represented by hiding the first band without appearance of characteristic bands in diabetic group. Therefore, the diabetic group was found with lower SI (90.91\%), and hence higher GD

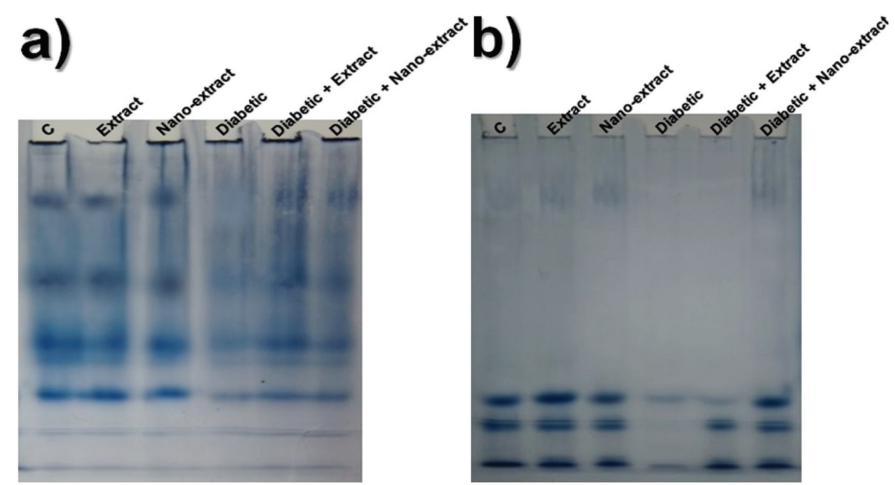

Figure 4. Electrophoretic lipoprotein patterns showing the curative effect of B. variegata extract before and after incorporating Au-NPs against STZ induced diabetes on (a) liver tissues and (b) pancreatic tissues of rats.

(9.09\%) (Fig. 5). The treatment with extract and nano-extract showed ameliorative effect against STZ-induced diabetes by reappearing the normal band. Therefore, the SI\% and GD restored to normal values $(100 \%$ and $0 \%$, respectively). Furthermore, data revealed in Figure 5 showed that STZ caused quantitative changes represented by lowering quantities of the total lipoprotein bands significantly $(p<0.05)$. The treatment with extract and nanoextract could not restore it to normal level.

In the pancreas tissue, the native lipoprotein pattern was expressed by four bands and two from them are considered as common bands [Rfs 0.77 and 0.95 (B\% 25.75 and 27.27; Q\% 25.23 and 23.20, respectively)]. No electrophoretic changes identified in pancreas of extract and nano-extract treated groups. In diabetic group, it was noticed absence of two normal bands without appearance of abnormal ones (Fig. 4b). Therefore, the diabetic group was found with the lowest SI (66.67\%), and hence the highest GD (33.33\%) as compiled in Figure 5. The treatment with extract restored only one normal band (SI: $85.71 \%$ and GD: $14.29 \%$ ). While the nano-extract showed higher ameliorative effect by restoring the two normal bands (SI: 100\% and GD: $0 \%$ ). In addition, it was showed that STZ caused quantitative changes represented by the significant $(p<0.05)$ decrease in quantities of the total lipoprotein bands. The treatment with extract and nano-extract increased quantities of the total lipoprotein bands significantly $(p<0.05)$ to normalcy as compared to D group.

\section{Native electrophoretic isoenzymes}

As illustrated in Figure 6a, the electrophoretic $\alpha$-amylase isoenzyme was expressed in the healthy liver tissue by two types identified at Rfs 0.23 and 0.73 (B\% 50.55 and 49.45; Q\% 49.08 and 50.92, respectively). The second type is considered as common band. No electrophoretic changes identified in livers of extract and nano-extract treated groups. In livers of diabetic group, it was found that STZ caused alterations represented by hiding the first type with appearance of two characteristic bands identified at Rf 0.16 and 0.38 (B\% 32.28 and 34.86 ; Q\% 26.36 and 36.37, respectively). Therefore, the diabetic group was found with the lowest SI $(40.0 \%)$, and hence the highest GD $(60.0 \%)$ as revealed in Figure 7 . The treatment with extract restored only one normal type with hiding the abnormal ones (SI: $66.67 \%$ and GD: $33.33 \%$ ). While the nano-extract showed 


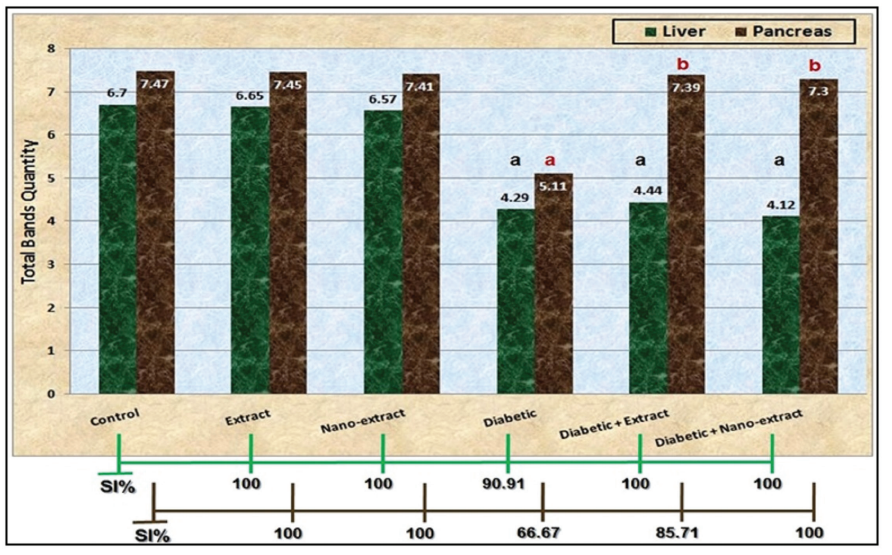

Figure 5. Data showing the ameliorative effect of $B$. variegata extract before and after incorporating Au-NPs against the quantitative and qualitative alterations induced by STZ in lipoprotein patterns in liver and pancreatic tissues of rats Values expressed as mean $\pm \mathrm{SE}$ of three replicates, (a) significant difference at $p<$ 0.05 from control group, (b) significant difference at $p<0.05$ from diabetic group.

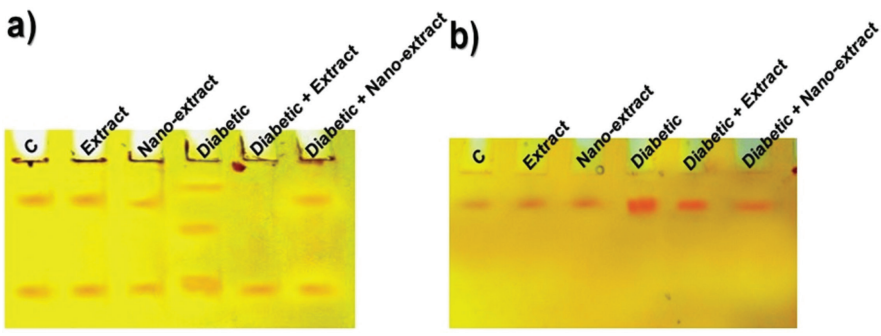

Figure 6. Electrophoretic $\alpha$-amylase isoenzymes showing the curative effect of B. variegata extract before and after incorporating Au-NPs against STZ induced diabetes on (a) liver tissues and (b) pancreatic tissues of rats.

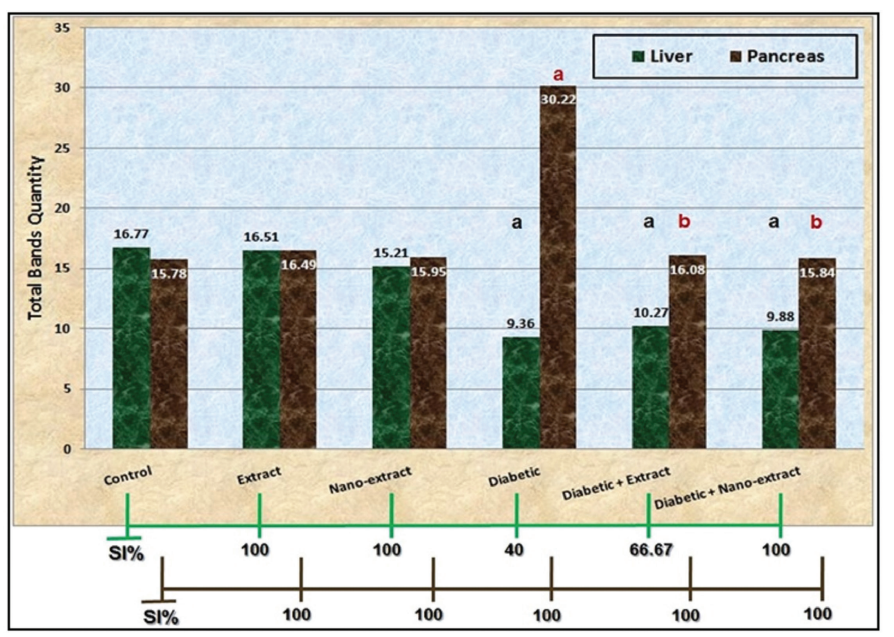

Figure 7. Data showing the ameliorative effect of $B$. variegata extract before and after incorporating Au-NPs against the quantitative and qualitative alterations induced by STZ in $\alpha$-amylase isoenzymes in liver and pancreatic tissues of rats. Values expressed as mean $\pm \mathrm{SE}$ of three replicates, (a) significant difference at $p<0.05$ from control group, (b) significant difference at $p<0.05$ from diabetic group.

higher ameliorative effect by restoring the two normal bands (SI: $100 \%$ and GD: $0 \%$ ). As regard to the quantities, it was noticed that STZ caused significant $(p<0.05)$ decrease in quantities of

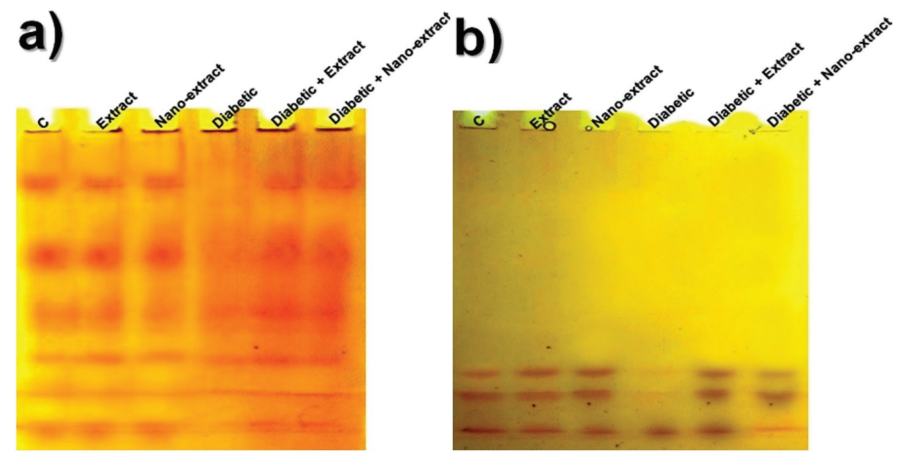

Figure 8. Electrophoretic CAT isoenzymes showing the curative effect of $B$. variegata extract before and after incorporating Au-NPs against STZ induced diabetes on (a) liver tissues and (b) pancreatic tissues of rats.

the $\alpha$-amylase types as compared to control group. The treatment with extract and nano-extract could not ameliorate these changes. In the pancreas tissue, the electrophoretic $\alpha$-amylase isoenzyme was represented by only one type identified as common band at Rfs 0.21 (B\% 100 ; Q\% 100, respectively) (Fig. 6b). In pancreas of diabetic group, it was found that STZ caused no alterations at qualitative level but it caused changes at quantitative level through increasing quantities of the $\alpha$-amylase band significantly $(p<0.05)$ as compared to control group (Fig. 7). The treatment with extract and nano-extract restored quantities of the $\alpha$-amylase types to normal level.

In control liver, it was noticed that CAT isoenzyme was represented electrophoretically by seven types and six from them are considered as common bands and identified at Rfs 0.39 , $0.57,0.71,0.82,0.92$ and 0.932 (B\% 19.45, 14.97, 10.23, 10.10, 11.37 and 18.83; Q\% 44.23, 17.24, 8.05, 8.52, 3.52 and 5.29, respectively) (Fig. 8a). In livers of diabetic group, it was found that STZ caused alterations represented by hiding the first type without appearance of abnormal ones. Therefore, the diabetic group was found with lower SI (92.31\%) and higher GD (7.69\%) as compiled in Figure 9. The treatment with extract and nano-extract showed restored the normal CAT type that disappeared by STZ. Therefore, the $\mathrm{SI} \%$ and GD restored to normal values $(100 \%$ and $0 \%$, respectively). It was showed that STZ caused quantitative changes represented by the significant $(p<0.05)$ decrease in quantities of the total CAT bands. The treatment with extract and nano-extract could not restore it to normal level but they significantly $(p<0.05)$ increased the bands quantity comparing to D group. The nanoextract showed higher ameliorative effect noticed by increasing the bands quantity significantly $(p<0.05)$ as compared to diabetic group treated with extract.

In the pancreas tissue, the CAT isoenzyme was expressed by four bands and two from them are considered as common bands [Rfs 0.94 and 0.95 (B\% 31.00 and 24.73; Q\% 18.04 and 18.23, respectively]. No deviation in CAT isoenzyme in pancreas of extract and nano-extract treated groups from control. In diabetic group, it was found that STZ caused absence of the first and second CAT types without appearance of abnormal bands (Fig. 8b). Therefore, the diabetic group was found with lower SI $(66.67 \%)$ and higher GD (33.33\%) as documented in Figure 9. The treatment with extract and nano-extract restored the normal CAT types, and hence restored SI and GD to normal values (SI: $100 \%$ and GD: 0\%). In addition, it was found that STZ caused 


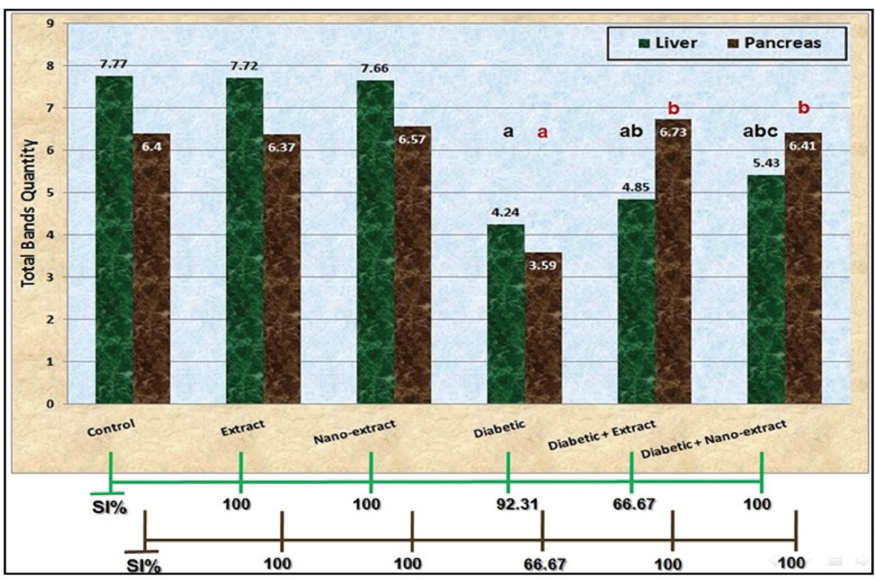

Figure 9. Data showing the ameliorative effect of $B$. variegata extract before and after incorporating Au-NPs against the quantitative and qualitative alterations induced by STZ in CAT isoenzymes in liver and pancreatic tissues of rats. Values expressed as mean $\pm \mathrm{SE}$ of three replicates, (a) significant difference at $p<0.05$ from control group, (b) significant difference at $p<0.05$ from diabetic group, (c) significant difference at $p<0.05$ from $B$. variegata extract treated group.

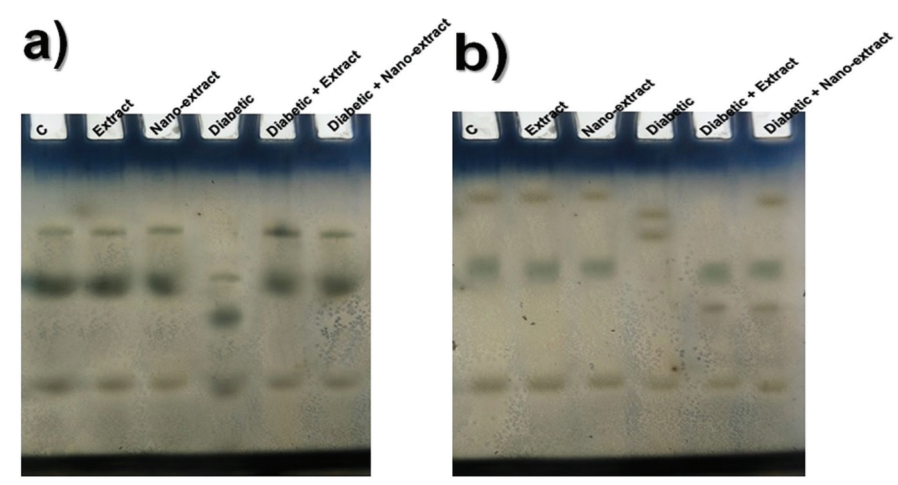

Figure 10. Electrophoretic POX isoenzymes showing the curative effect of $B$. variegata extract before and after incorporating Au-NPs against STZ induced diabetes on (a) liver tissues and (b) pancreatic tissues of rats.

quantitative changes represented by decreasing quantity of the total CAT bands significantly $(p<0.05)$. The extract and nanoextract significantly $(p<0.05)$ increased quantities of the CAT bands comparing to D group. The nano-extract showed higher ameliorative effect through significantly $(p<0.05)$ increasing the bands quantity as compared to D group treated with extract and restored its level to normal values.

As presented in Figure 10a, the native POX isoenzyme was represented electrophoretically in healthy liver tissue by three types and only one of them is considered as common band ( $\mathrm{Rf}$ $0.77, \mathrm{~B} \%$ 33.52, and $\mathrm{Q} \%$ 32.88). No electrophoretic abnormalities noticed in livers of extract and nano-extract treated groups. In livers of diabetic group, it was found that STZ caused qualitative alterations represented by hiding the first and second POX types with existence of two characteristic bands identified at Rfs 0.43 and 0.55 (B\% 28.72 and 36.04; Q\% 21.12 and 50.97, respectively). Therefore, the diabetic group was noticed with the lowest SI (33.33\%), and hence the highest GD\% (66.67\%) as illustrated in Figure 11. The treatment with extract and nano-extract exhibited beneficial effect against STZ-induced diabetes by hiding the

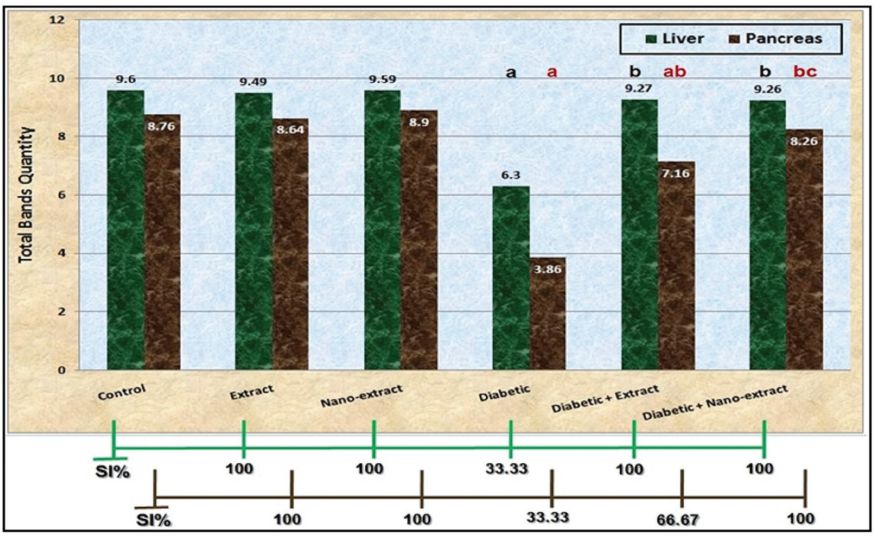

Figure 11. Data showing the ameliorative effect of $B$. variegata extract before and after incorporating Au-NPs against the quantitative and qualitative alterations induced by STZ in POX isoenzymes in liver and pancreatic tissues of rats. Values expressed as mean $\pm \mathrm{SE}$ of three replicates, (a) significant difference at $p<0.05$ from control group, (b) significant difference at $p<0.05$ from diabetic group, (c) significant difference at $p<0.05$ from $B$. variegata extract treated group.

abnormal bands associated with re-appearing the normal ones. Therefore, the SI\% and GD restored to normal values $(100 \%$ and $0 \%$, respectively). It was found that STZ caused quantitative changes represented by the significant $(p<0.05)$ decrease in quantities of the total POX bands. The treatment with extract and nano-extract restored the bands quantities to normal level.

In the pancreas tissue, POX isoenzyme was expressed by three types. The third type is considered as common band [Rfs 0.78 (B\% 31.49 and Q\% 41.51)]. No deviation in POX isoenzyme in pancreas of extract and nano-extract treated groups from control. STZ caused absence of the first and second POX types with appearance of two abnormal bands identified at Rfs 0.24 and 0.31 (B\% 33.75 and 32.48; Q\% 28.99 and 37.86, respectively) (Fig. 10b). Therefore, the diabetic group was found with the lowest SI (33.33\%), and hence the highest GD (66.67\%) as presented Figure 11. The treatment with extract restored only one normal type with hiding one abnormal band (SI: 66.67\% and GD: $33.33 \%$ ). While the nano-extract exhibited a higher ameliorative effect by restoring the two normal bands (SI: $85.71 \%$ and GD: $14.29 \%$ ). Moreover, STZ caused quantitative changes represented by lowering quantities of the total POX bands significantly $(p$ $<0.05)$. The extract and nano-extract significantly $(p<0.05)$ increased quantities of the total bands as compared to D group. The nano-extract showed higher ameliorative effect noticed by increasing the bands quantity significantly $(p<0.05)$ comparing to $\mathrm{D}+\mathrm{E}$ and restored the bands quantities to normal values.

\section{Histopathological study}

As presented in Figure 12, it was noticed that diabetic group appeared with fibrosis associated with inflammatory cells infiltration, congestion in the portal area, and dilatation in central vein. This was in accordance with Teoh et al. (2009) who postulated that involvement of the hepatocytes with features of inflammation in diabetic rats. The treatment with $B$. variegata extract and $B$. variegata- gold nano-extract ameliorate the histopathological changes, especially in the diabetic group that treated with nanoextract where it appeared with normal architecture like control. 

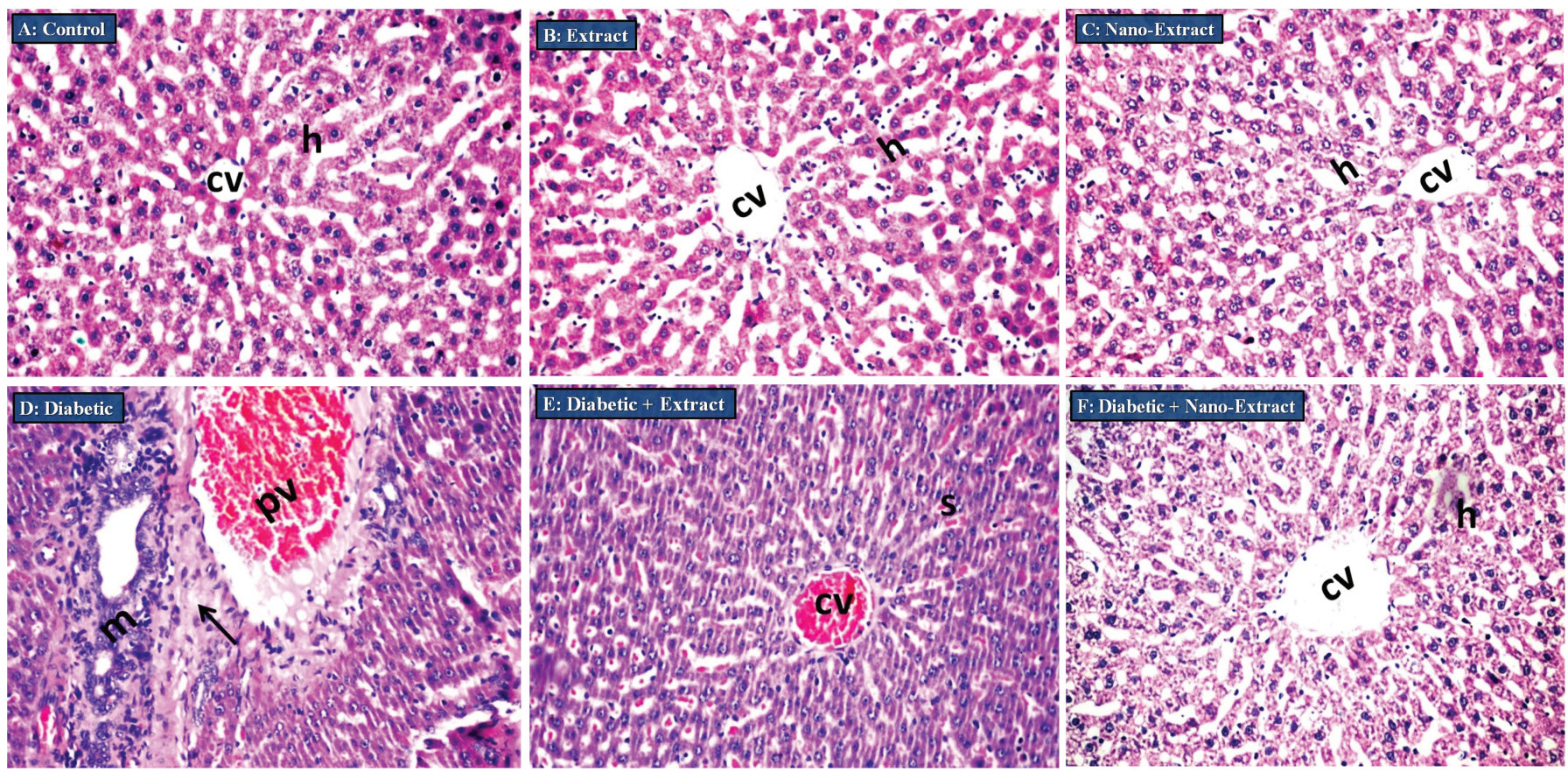

Figure 12. (A) Section of liver of control group showed normal architecture of hepatocytes $(\mathrm{h}),(\underline{\mathbf{B}})$ Section of liver of extract treated group showed normal hepatic lobule and hepatocytes, $(\underline{\mathbf{C}})$ Section of liver of nano-extract treated group showed no histopathological changes as in control group, $(\underline{\mathbf{D}})$ Section of liver of diabetic group showed fibrosis in the portal area (arrow) with inflammatory cells infiltration (m) and congestion in the portal vein (pv), as well as, dilatation and congestion in the central veins $(\mathrm{cv}),(\underline{\mathbf{E}})$ Section of liver of diabetic group treated with extract showed mild congestion in the central vein and sinusoids, $(\underline{\mathbf{E}})$ Section of liver of diabetic group treated with nano-extract showed no histopathological alteration in hepatic architecture as in control group (H\&E $\times 16)$.

The histopathological analysis of pancreatic tissue showed that there was no histopathological alteration in control group where the islets of Langerhans as endocrine portion as well as the acini and ducts system as exocrine one were recorded. The un-toxic effect of ethanolic extract and gold nano-extract were confirmed when compared both groups with control group where, no histological alterations were detected (Fig. 13).

It was showed that either complete absence of islets of Langerhans cells in some diabetic samples or atrophy in most of islands of Langerhans cells all over the lobules and only few islets cells were intact in other diabetic samples (Fig. 13). The treatment with both ethanolic extract and gold nano-extract restored the normal structure of pancreatic $\beta$-cells indicating the protective effect of both of them on pancreatic tissue.

\section{DISCUSSION}

The available synthetic antidiabetic drugs (insulin and other oral anti-diabetic agents) were associated with side effects, such as hypoglycemia and diarrhea in addition to failure of liver and kidney (Zhang et al., 2016). It was necessary to study the potential benefits of different plant extracts for diabetes management (Ogunyinka et al., 2015). Nanotechnology is emerged as a new strategy that used to increase the efficacy and bioavailability of medicinal plants (Gunasekaran et al., 2014). Recently, scientists have come to be increasingly interested in preparation of Au-NPs, owing to their special physical and chemical properties in extensive areas like catalysis, biolabeling, drug delivery, and packaging applications (Daniel and Astruc, 2004; Pal et al., 2013; Youssef and El-Sayed, 2018). Our study aimed to evaluate the effect of the integration of Au-
NPs in B. variegata extract on its antidiabetic, antioxidant, and hypolipidemic effect in DM induced rats.

During the present study, it was found that ethanolic $B$. variegata leaves extract showed the highest concentration of total polyphenols, total antioxidant capacity, iron reducing power, and scavenging activity against free radicals attack as compared to the other plant extracts. Our results were in accordance with Kalim and Nikalje (2017) who supported that the ethanolic extract of this plant exhibited high scavenging activity against both Reactive Oxygen (ROS) and Nitrogen Species (RNS). This might be attributed to presence of the active phenolic compounds, including quercetin, naringenin, rutin, and luteolin that exhibit redox properties letting them to act as hydrogen donors and reducing agents (Abdel-Aziz et al., 2014). In addition, Mishra et al. (2013) reported that the various B. variegata leaves extracts possess potent capability to combat the oxidative stress due to its iron binding, radical neutralization and reducing power ability.

During the current study, it was found that $B$. variegatagold nano-extract showed higher concentration of active components (total phenolic compounds and total flavonoids). This was in agreement with Alegria et al. (2018) who reported that amount of the polyphenols increased in the extract during the preparation of nano-extract indicating their effective involvement in nanoparticles synthesis. These findings were supported by many recent studies, which explained that the integration of metal nanoparticles into the plant extract increased the active phyto-constituents. Consequently, this leads to elevating its total antioxidant ability, iron reducing power, and hence increasing the free radicals scavenging ability as compared to the plant extract alone (Abdelhady and Badr, 2016; Aboulthana et al., 2019). 


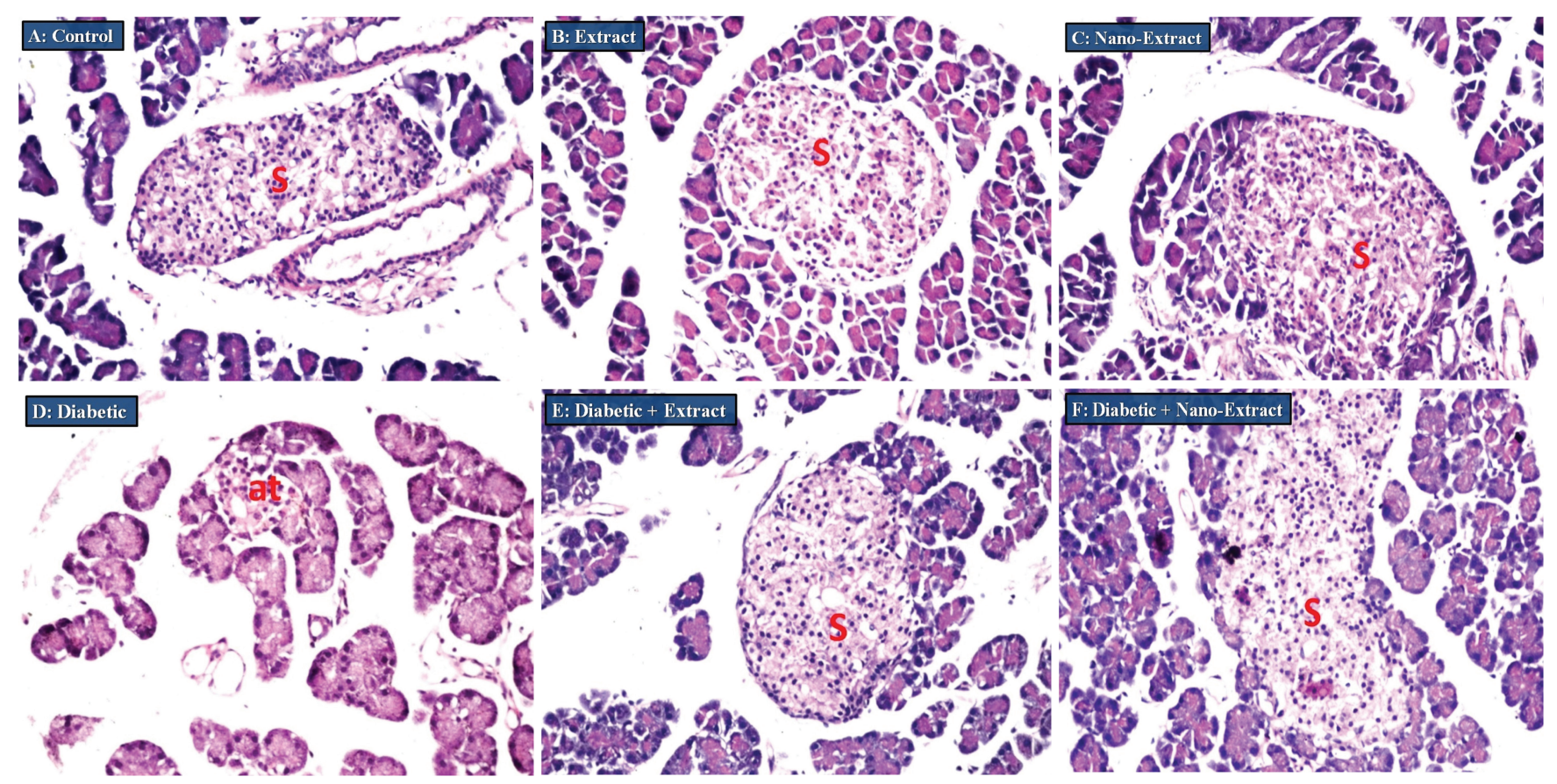

Figure 13. (A) Section of pancreas of control group showing normal histological structure of islands of Langerhans cells as endocrine portion as well as the acini with duct system as exocrine one $(\mathrm{H} \& \mathrm{E} \times 40),(\mathbf{B})$ Section of pancreas of extract treated group, $(\mathbf{C})$ Section of pancreas of nano-extract treated group showed normal histological structure of islands of Langerhans and no histopathological changes as in control group, (D) Section of pancreas of diabetic group showing atrophy (at) in most of islands of Langerhans cells all over the lobules. In other field, it showed intact few islands of Langerhans cells or complete absence of the islands of Langerhans cells in the lobules, ( $\mathbf{E})$ Section of pancreas of diabetic group treated with extract and (F) diabetic group treated with nano-extract showed no histopathological alterations in pancreatic architecture as in control group $(\mathrm{H} \& \mathrm{E} \times 40)$.

Our results showed that body weight was decreased in D group with respect to control group. This might be due to the inability for utilizing carbohydrates to get energy because of the deficient in insulin secretion. Therefore, the body directed to get energy through degradation of fats and muscles (proteins) as reported by Choudhary et al. (2014). While the improvement in body weight after treatment with both the extract and nanoextract indicated the improvement in insulin secretion, which was in agreement with the results that obtained by Hassan et al. (2015) and supported by Kulkarni and Garud (2016).

The present study showed a significant elevation in blood glucose associated with a decreasing in insulin level in diabetic rats as compared to control group. This attributed to the effect of STZ, which lead to destruction of $\beta$ cells of pancreatic islets and then reduction in insulin release. This was in accordance with Roder et al. (2016) who mentioned that the reduction in insulin secretion decreased glucose entry into tissues, increased glycogen breakdown, gluconeogenesis and glucose production by liver, and finally increased blood glucose levels.

Levels of glucose decreased and insulin increased after treatment with both extract and nano-extract, which might be due to the presence of polyphenols in our extract, which enhance glucose uptake. In accordance with our results, Naowaboot et al. (2012) and Mohan et al. (2013) showed that the presence of different active components as tannins and quercetin improve the efficacy of $B$. variegata extract to restore the integrity of $\beta$ - cells of pancreas and hence upturn glucose uptake and metabolism. Moreover, Frankish et al. (2010) and Kumar et al. (2012) reported that $B$. variegata extract was found to activate insulin secretion in insulin secreting cell line. In addition, Rashid (2014) added that $B$. variegata leaves contain insulin-like protein, which might be responsible for its antidiabetic effect, where plant and animal insulin share metabolic functions as carbohydrate metabolism regulation, protein phosphorylation, and transporting glucose into tissues.

The $\alpha$-amylase is a digestive enzyme found mainly in saliva and pancreatic juice. It hydrolyses $\alpha$-(1,4)-D-glycosidic linkages of dietary carbohydrates as starch and other glucose polymers to oligosaccharides and disaccharides, which then hydrolyzed to monosaccharides and absorbed through the small intestine (Najafian et al., 2011). The current study showed that STZ caused significant decrease in the $\alpha$-amylase quantity in livers of diabetic rats. This was in accordance with Mufeed et al. (2014) and supported by Udia et al. (2016) who reported that the enzyme quantity decreased due to the hormonal and metabolic alterations sequel to diabetes. Moreover, STZ caused alterations at qualitative level through changing the number and arrangement of the bands and hence leads to lowering the SI\%. Otherwise, it was observed that STZ caused a significant increase in quantities of the $\alpha$-amylase bands and it was represented by only one thick band in pancreas of diabetic rats. It was reported that the enzyme quantity increased due to the abnormal effectiveness of the acinar pancreatic cells to biosynthesize this enzyme or its effective role in glucose hydrolysis (Kamarýt et al., 1993; Aboulthana et al., 2018). The treatment with extract before and after incorporating $\mathrm{Au}-\mathrm{NPs}$ ameliorated the qualitative and quantitative abnormalities in the electrophoretic $\alpha$-amylase pattern. Azevedo et al. (2006) attributed this amelioration effect of $B$. variegata leaves extract to 
its antidiabetic effect, which is related to the presence of insulinlike proteins. In addition, the presence of active constituents as phenolic compounds inhibits $\alpha$-amylase activity due to their free radical scavenging and antioxidant activities (Rao and Mohan, 2017).

Diabetes is linked to hyperglyceridemia and hypercholesterolemia, which represents high risk factors for atherosclerotic disease (Andallu et al., 2009). Insufficient insulin secretion leads to inactivation of lipoprotein lipase, which is responsible for TGs hydrolysis, which consequently leads to increasing in TGs levels. The TGs increases secretion of LDL-c and decreases HDL-c. In the present work, it was found that levels of TGs, TC, LDL-c were significantly increased associated with a decreasing in HDL-c in D group as compared to control group, while treatment with both $B$. variegata extract and gold nanoextract decreased TGs, TC, LDL-c levels, and increased HDL-c. This might be due to presence of the various phenolic compounds in our extract. In accordance of our results, Dhanya et al. (2014) mentioned that rutin and quercetin were responsible for enhancing glucose uptake.

The results showed that serum TP level was decreased and the electrophoretic protein and lipoprotein patterns was found to be altered in diabetic group as compared to control group which may be due to the action of STZ which causes damage of proteins by free radicals induction. In accordance with our results, Karthikesan et al. (2010) and Bhargavi et al. (2015) explained that the decline in TP was due to the elevation of glucose level, which leads to glycosylation of proteins and lipoproteins through the reaction of glucose with the protein portions. Furthermore, Blasiak et al. (2004) and Aboulthana et al. (2018) postulated that these electrophoretic changes may occur because of the reduction of the antioxidant activities, and hence accumulation of oxidative stress products.

The treatment with gold $B$. variegata nano-extract decreased the qualitative and quantitative disturbances induced by STZ on the electrophoretic protein, lipoprotein patterns, and serum TP level more than B. variegata extract itself as compared to diabetic group. This might be attributed to the presence of various active phyo-constituents that increased after incorporating Au-NPs as supported during the current study. The presence of the polyphenolic compounds in the extract exhibited antihyperglycemic effect by reducing the blood glucose level, and hence the alterations that occurred as a result of the glycosylation process might be decreased by the extract (Shanmugasundaram et al., 1990). The Au-NPs incorporated into the extract are carried across the cell membrane as they are very small in size and have a prolonged effect in biological systems (Govindaraju et al., 2009).

Liver is considered as one of the central metabolic organs, which play a vital role in regulating and maintaining homeostasis in the body. Diabetes is closely linked to structural and functional liver abnormalities as well as impairment of the pancreas. The changes in target proteins and lipid metabolism as well as in the antioxidant status in liver are the most common abnormalities that are usually associated with diabetes (Saxena et al., 1993; Zeindl-Eberhart et al., 2001).

Results of the current study showed that AST, ALT, and ALP activities were significantly elevated in D group comparing to the control group. This increase might be due to the cellular damage that caused by STZ which causes leakage of liver enzymes into the blood stream. These findings agreed with Zafar et al. (2009) and Kasetti et al. (2010) who documented that STZ causes liver injury leading to release of the enzymes, and hence increased their levels in the blood. There was a significant decrease in liver enzymes in $\mathrm{D}+\mathrm{E}$ and $\mathrm{D}+\mathrm{N}$ treated groups comparing to $\mathrm{D}$ group, indicating the hepato-protective effect of ethanolic $B$. variegata extract and nano-extract. The un-toxic effect of the ethanolic extract or the nano-extract on the animals was noticed as liver enzymes in $\mathrm{E}$ and $\mathrm{N}$ treated groups as in control group.

Increased urea and creatinine in diabetes indicating impairment of kidney functions (Ronco et al., 2010). Our results showed an increment in urea and creatinine levels in STZ-induced diabetic animals as compared to control group. In agreement with our results Hassan et al. (2015) showed that the elevation of urea and creatinine might be due to increased protein catabolism. Ethanolic extract and gold nano-extract of $B$. variegata attenuate the levels of urea and creatinine comparing to diabetic group, which may be due to the antioxidant properties of the extract.

When the balance between ROS generation and ROS scavenging systems is lost, oxidative stress was evolved. The continuous free radicals production that associated with hyperglycemia will eventually cause cellular damage or dysfunction as lipid peroxidation, protein glycation, and glucose autoxidation. Enzymatic and non-enzymatic antioxidants are responsible for the protection of the body against free radicals attack by converting them to less toxic compounds (Ahmed, 2005; Mohan et al., 2013). The present study showed that hepatic and pancreatic antioxidant enzyme activities (CAT, SOD), and GSH level were decreased and lipid peroxidation was increased in D group as compared to control group which due to the induction of free radicals by STZ. Our results were in agreement with Rahman (2007) who mentioned that the enzymatic and non-enzymatic antioxidants were decreased in DM because of their consumption to attenuate oxidative stress. Furthermore, STZ caused alterations in the different electrophoretic CAT and POX isoenzymes in both of liver and pancreas of diabetic rats. This was in agreement with Oyenihi et al. (2015) and Chandirasegaran et al. (2018). This might be due to degeneration of protein contents or changes in the metabolic pathways because of free radicals attack in addition to the glycation process, which inhibits activity of these enzymes (Ramanathan et al., 1999; Al-Enazi, 2014).

Treatment of diabetic rats with either extract or gold nano-extract of $B$. variegata improved the antioxidant defense system through increasing levels of antioxidants, decreasing TBARS (lipid peroxidation product) level and ameliorating the alterations in electrophoretic CAT and POX isoenzymes in both liver and pancreas as compared to diabetic group. This might be due to presence of the active phyto-constituents that exhibited antioxidant properties and increased after incorporating nanoparticles. Different studies suggested that antioxidant defense mechanisms in pancreatic islets could protect from diabetes. It was explained that $B$. variegata has a free radical scavenging activity due to its phenolic contents as quercetin, rutin, and kaempferol (Rashid, 2014; Sheweita et al., 2016; Kalim and Nikalje, 2017). Dixon and Palva (1995) explained that these phenolic compounds are the first line of a complex defense system against different stressors. 
Our biochemical and electrophoretic studies were supported by the histopathological investigation which revealed that the treatment with both extract and nano-extract ameliorated the deleterious alterations that induced by STZ in hepatic and pancreatic tissues.

\section{CONCLUSION}

The incorporation of Au-NPs into the B. variegata extract improved its efficacy, where its polyphenolic contents, total antioxidant activity, iron reducing power, and scavenging activity against free radicals attack were increased as compared to extract only. Therefore, the $B$. variegata gold nano-extract exerted more efficient anti-diabetic effect through restoring the normal architecture of pancreatic $\beta$-cells in addition to the antioxidant and hypolipidemic activity against STZ-induced diabetes in rats than extract alone.

\section{DECLARATIONS}

\section{Author contribution}

Abeer Hamed Abdel-Halim and Mamdouh Mouad Ali Hassan proposed the research concept. Abeer Hamed AbdelHalim and Amal Abdel-Azeem Fyiad performed the extraction and designed the experimental model. Wael Mahmoud Aboulthana collected plant samples, performed phytochemistry studies, and helped in analyzing data. Abeer Hamed Abdel-Halim, Amal Abdel-Azeem Fyiad, Wael Mahmoud Aboulthana, and Nermin Mohammed El-Sammad performed the experimental work and provided reagents/materials necessary for experiments. Amal Abdel-Azeem Fyiad and Wael Mahmoud Aboulthana helped in writing the manuscript

Ahmed Mahmoud Youssef was responsible for the preparation of the gold nano-extract and analyzing its data.

Abeer Hamed Abdel-Halim interpreted, analyzed the data, wrote, and correspond the manuscript.

All authors read and approved the final manuscript.

\section{Funding statement}

There was no fund provided to this work.

\section{Conflict of interest}

The authors declare no potential conflicts of interest with respect to the research, authorship, and/or publication of this article.

\section{Additional information}

No additional information is available for this
manuscript.

\section{REFERENCES}

Abdel-Aziz MS, Shaheen MS, El-Nekeety AA, AbdelWahhab MA. Antioxidant and antibacterial activity of silver nanoparticles biosynthesized using Chenopodiummurale leaf extract. J Saudi Chem Soc, 2014; 18(4): 356-63.

Abdelhady NM, Badr KA. Comparative study of phenolic content, antioxidant potentials and cytotoxic activity of the crude and green synthesized silver nanoparticles' extracts of two Phlomis species growing in Egypt. J Pharmacogn Phytochem, 2016; 5:377-83.

Aboulthana WM, El-Feky AM, Ibrahim NE, Sahu RK, ElSayed AB. Evaluation of the pancreatoprotective effect of Nannochloropsis oculata extract against streptozotocin-induced diabetes in rats. J Appl Pharm Sci, 2018; 8:046-58.
Aboulthana WM, Youssef AM, El-Feky AM, Ibrahim NE, Seif MM, Hassan AK. Evaluation of antioxidant efficiency of Croton tiglium L. seeds extracts after incorporating silver nanoparticles. Egypt J Chem, 2019; 62:181-200.

Aebi H. Catalase in vitro, Methods Enzymol, 1984; 105:121-6.

Ahmed RG. The physiological and biochemical effects of diabetes on the balance between oxidative stress and antioxidant defense system. Med J Islamic World Acad Sci, 2005; 15:31-42.

Akbarzadeh A. Induction of diabetes by streptozotocin in rats. Indian J Clin Biochem, 2007; 22:60-4.

Alegria ECBA, Ribeiro APC, Mendes M, Ferraria AM, do Rego AMB, Pombeiro AJL. Effect of phenolic compounds on the synthesis of gold nanoparticles and its catalytic activity in the reduction of nitro compounds. Nanomaterials (Basel), 2018; 8:320.

Al-Enazi MM. Combined therapy of rutin and silymarin has more protective effects on streptozotocin-induced oxidative stress in rat. J Appl Pharm Sci, 2014; 4:021-8.

Ali MM, Agha FE. Amelioration of streptozotocin-induced diabetes mellitus, oxidative stress and dyslipidemia in rats by tomato extract lycopene. Scand J Clin Lab Invest, 2009; 69: 371-9.

Andallu B, Vinay Kumar AV, Varadacharyulu NCh. Lipid abnormalities in streptozotocin-diabetes: amelioration by Morusindica L. cv Suguna leaves. Int NCh J Diabetes Dev Ctries, 2009; 29: 123-8.

Archana S, Rashmi N, Khemani LD. Hypoglycemic effect of Hibiscus rosasinensis L. leaf extract in glucose and streptozotocin induced hypoglycemic rats. Indian J Ex Biol, 2001; 39:284-6.

Azevedo CR, Maciel FM, Silva LB, Ferreira AT, da Cunha M, Machado OL, et al. Isolation and intracellular localization of insulin-like proteins from leaves of Bauhinia variegate. Braz J Med Biol Res, 2006; 39:1435-44.

Balde ES, Balde NM, Traore MS, Diallo MA, Camara IV, Diallo MST, et al. Efficacy and safety of Englerinalecardii (Engl.) Balle in the treatment of type 2 diabetes. J Plant Sci, 2015; 3:24-7.

Banchroft JD, Stevens A, Turner DR. Theory and practice of histological techniques. 4th edition, Churchil Livingstone, New York, London, San Francisco, Tokyo, 1996.

Beutler E, Duron O, Kelly BM. Improved method for the determination of blood glutathione. J Lab Clin Med, 1963; 61:882-90.

Bhargavi G, Josthna P, Naidu CV. Changes in serum biochemical parameters and lipid profile in normal and STZ-induced diabetic rats with the administration of ethanolic extract of polyalthiacerasoides stem bark. Int Res J Pharm, 2015; 6:153-6.

Blasiak J, Arabski M, Krupa R, Wozniak K, Zadrozny M, Kasznicki J, et al. DNA damage and repair in type 2 diabetes mellitus. Mutat Res, 2004; 554:297-304.

Bonifácio BV, da Silva PB, dos Santos Ramos MA, Negri KMS, Bauab TM, Chorilli M. Nanotechnology-based drug delivery systems and herbal medicines: a review. Int J Nanomedicine, 2014; 9:1-15.

Bradford MM. A rapid and sensitive method for the quantitation of microgram quantities of protein utilizing the principle of protein-dye binding. Anal Biochem, 1976; 72:248-54.

Brand-Williams W, Cuvelier ME, Berset C. Use of a free radical method to evaluate antioxidant activity. Lebenson Wiss Technol, 1995; 28:25-30.

Brenna O, Qvigstad G, Brenna E, Waldum HL. Cytotoxicity of streptozotocin on neuroendocrine cells of the pancreas and the gut. Dig Dis Sci, 2003; 48:906-10.

Chandirasegaran G, Elanchezhiyan C, Ghosh K. Effects of Berberine chloride on the liver of streptozotocin-induced diabetes in albino Wistar rats. Biomed Pharmacother, 2018; 99:227-36.

Choudhary M, Aggarwal N, Choudhary N, Gupta P, Badhwar V. Effect of aqueous and alcoholic extract of Sesbaniasesban (Linn.) Merr. Root on glycemic control in streptozotocin-induced diabetic mice. Drug Dev Ther, 2014; 5:115-22.

Daniel MC, Astruc D. Gold nanoparticles: assembly, supramolecular chemistry, quantum-size-related properties, and applications toward biology, catalysis, and nanotechnology. Chem Rev, 2004; 104:293-346. 
Darwesh OM, Moawad H, Barakat OS, Abd El-Rahim WM. Bioremediation of textile reactive blue azo dye residues using nanobiotechnology approaches. Res J Pharm Biol Chem Sci, 2015; 6: 1202-11.

Dhanya R, Arun KB, Syama HP, Nisha P, Sundaresan A, Santhosh Kumar TR, Jayamurthy P. Rutin and quercetin enhance glucose uptake in L6 myotubes under oxidative stress induced by tertiary butyl hydrogen peroxide. Food Chem, 2014; 158:546-54.

Dixon RA, Palva N. Stress-induced phenylpropanoid metabolism. Plant Cell, 1995; 7:1085-97.

Elia P, Zach R, Hazan S, Kolusheva S, Porat Z, Zeiri Y. Green synthesis of gold nanoparticles using plant extracts as reducing agents. Int J Nanomedicine, 2014; 9:4007-21.

Frankish N, de Sousa MF, Mills C, Sheridan H. Enhancement of insulin release from the beta-cell line INS-1 by an ethanolic extract of Bauhinia variegata and its major constituent roseoside. Planta Med, 2010; 76:995-7.

Gaber SA, Elsayed ZI. Biological evaluation of leaves extract of Bauhinia variegate in alloxan-induced diabetic rats. Isotope Rad Res, 2010; 42, 4:1143-52.

Gandhi GR, Sasikumar P. Antidiabetic effect of Merremiaemarginata Burm. F. in streptozotocin induced diabetic rats. Asian Pac J Trop Biomed, 2012; 2:281-6.

Govindaraju K, Kiruthiga V, Kumar VG, Singaravelu G. Extracellular synthesis of silver nanoparticles by a marine alga, Sargassumwightii Grevilli and their antibacterial effects. J Nanosci Nanotechnol, 2009; 9:5497-501.

Guariguata L. Estimating the worldwide burden of type 1 diabetes. Diabetes Voice, 2011; 56:6-7.

Gunasekaran T, Haile T, Nigusse T, Dhanaraju MD. Nanotechnology: an effective tool for enhancing bioavailability and bioactivity of phytomedicine. Asian Pac J Trop Biomed 2014; 4:S1-S7.

Hames BD. One-dimensional polyacrylamide gel electrophoresis. In: Hames BD, Rickwood D. Gel electrophoresis of proteins: B.D. 2nd edition, Oxford University press, New York, NY, pp 1-147, 1990.

Hassan SK, El-Sammad NM, Mousa AM, Mohammed MA, Farrag AH, Hashim AN, et al. Hypoglycemic and antioxidant activities of CaesalpiniaferreaMartius leaf extract in streptozotocin-induced diabetic rat. Asian Pac J Trop Biomed, 2015; 5:462-71.

Kalim S, Nikalje APG. A brief review on Bauhinia variegata: phytochemistry, antidiabetic and antioxidant potential. Am J Pharm Tech Res, 2017; 7:186-97.

Kamarýt J, Stejskal J, Osicková L, Mrskos A, Pribylová H, Coupek P. Urinary amylase isoenzymes and amylase polymorphism variants in families with diabetes mellitus type 1. Eur J Clin Chem Clin Biochem, 1993; 31:739-42.

Karthikesan K, Pari L, Menon VP. Chemico-biological interactions antihyperlipidemic effect of chlorogenic acid and tetrahydrocurcumin in rats subjected to diabetogenic agents. Chem Biol Interact, 2010; 188:643-50.

Kasetti RB, Rajasekhar MD, Kondeti VK, Shaik SF, Ethamakula GTK, Sirasanagandla S, et al. Antihyperglycemic and antihyperlipidemic activities of methanol: water (4:1) fraction isolated from aqueous extract of Syzygiumalternifolium seeds in streptozotoc induced diabetic rats. Food Chem Toxicol, 2010; 48:1078-84.

Kulkarni YA, Garud MS. Bauhinia variegata (Caesalpiniaceae) leaf extract: an effective treatment option in type I and type II diabetes. Biomed Pharmacother, 2016; 83:122-9.

Kulkarni YA, Garud MS. Effect of Bauhinia variegata Linn. (Caesalpiniaceae) extract in streptozotocin induced type I diabetic rats. Orient Pharm Exp Med, 2015; 15:191-8.

Kumar P, Baraiya S, Gaidhani SN, Gupta MD, Wanjari MM. Antidiabetic activity of stem bark of Bauhinia variegata in alloxan-induced hyperglycemic rats. J Pharmacol Pharmacother, 2012; 3:64-6.

Kumar R, Arora V, Ram V, Bhandari A, Vyas P. Hypoglycemic and hypolipidemic effect of Allopolyherbal formulations in streptozotocin induced diabetes mellitus in rats. Int J Diabetes Mellit, 2015; 3:40-5.
Lefevre GM, Beljean-Leymarie F, Beyerle D, BonnefontRousselot JP, Cristol P, Therond Torreilles J. Evaluation of lipid peroxidation by measuring thiobarbituric acid reactive substances. Ann Biol Clin (Paris), 1998; 56:305-19 (In French).

Mamillapalli V, Atmakuri AM, Khantamneni P. Nanoparticles for herbal extracts. Asian J Pharm, 2016; 10:S54-S60.

Minami M, Yoshikawa HA. Simplified assay method of superoxide dismutase activity for clinical use. Clin Chim Acta, 1979, 92:337-42.

Mishra A, Sharma AK, Kumar S, Saxena AK, Pandey AK Bauhinia variegata leaf extracts exhibit considerable antibacterial, antioxidant, and anticancer activities. Biomed Res Int, 2013;2013:915436. doi: $10.1155 / 2013 / 915436$

Mohan Y, Jesuthankaraj GN, Thangavelu NR. Antidiabetic and antioxidant properties of Triticumaestivum in streptozotocin-induced diabetic rats. Adv Pharmacol Sci, 2013;2013:716073. doi: 10.1155/2013/716073.

Mufeed JE, Thana MJ, Zinah AA, Muna ME. Evaluation of amylase activity in patients with type 2daibetes mellitus. Am J Bio Sci, $2014 ; 2: 171-4$

Najafian M, Jahromi MZ, Nowroznejhad MJ, Khajeaian P, Kargar MM, Sadeghi M, et al. Phloridzin reduces blood glucose levels and improves lipids metabolism in streptozotocin-induced diabetic rats. Mol Biol Rep, 2011; 1:1-8.

Naowaboot J, Pannangpetch P, Kukongviriyapan V, Prawan A Kukongviriyapan U, Itharat A. Mulberry leaf extract stimulates glucose uptake and GLUT4 translocation in rat adipocytes. Am J Chin Med, 2012; 40:163-75.

Ogunyinka BI, Oyinloye BE, Adenowo AF, Kappo AP. Potentials of some plant-derived foods in the management of diabetes and associated Complications. Afr J Tradit Complem. Altern Med, 2015; 12:12-20.

Oyaizu M. Studies on product of browning reaction prepared from glucose amine. Japan J Nutr, 1986; 44:307-15.

Oyenihi OR, Brooks NL, Oguntibeju OO. Effects of kolaviron on hepatic oxidative stress in streptozotocin induced diabetes. BMC Complement Altern Med, 2015; 15:236.

Paget GE, Barnes JM. Toxicity tests. In: Laurance DR, Bacharach $\mathrm{AL}$, (eds.). Evaluation of drug activities: pharmacometrics, Vol 1. Academic Press, New York, NY, pp 135-65, 1964.

Pal R, Panigrahi S, Bhattacharyya D, Chakraborti AS Characterization of citrate capped gold nanoparticle-quercetin complex: experimental and quantum chemical approach. J Mol Struct, 2013; 1046:153-63

Prasad R. Synthesis of silver nanoparticles in photosynthetic plants. J Nanoparticles, 2014; 2014:963961. doi: 10.1155/2014/963961.

Prieto P, Pineda M, Aguilar M. Spectrophotometric quantitation of antioxidant capacity through the formation of a phosphomolybdenum complex: specific application to the determination of vitamin E. Ana Biochem, 1999; 269:337-41.

Rahman K. Studies on free radicals, antioxidants, and co-factors. Clin Interv Aging, 2007; 2:219-36.

Ramanathan M, Jaiswal AK, Bhattacharya SK. Superoxide dismutase, catalase and glutathione peroxidase activities in the brain of streptozotocin induced diabetic rats. Indian J Exp Biol, 1999; 37:182-3.

Rammesmayer G, Praznik W. Fast and sensitive simultaneous staining method of Q-enzyme, $\alpha$-amylase, R-enzyme, phosphorylase and soluble starch synthase separated by starch: polyacrylamide gel electrophoresis. J Chromatogr, 1992; 623:399-402.

Rao PS, Mohan GK. In vitro alpha-amylase inhibition and in vivo antioxidant potential of Momordicadioica seeds in streptozotocininduced oxidative stress in diabetic rats. Saudi J Biol Sci, 2017; 24:1262-7.

Rashid KI. Detection of insulin-like protein and some active compounds in Bauhinia Variegata linn. Leaf ethanolic extracts and the effect in reducing blood glucose levels in mice. IOSR J Pharm, 2014; 4: $01-5$.

Rescigno A, Sanjust E, Montanari L, Sollai F, Soddu G, Rinaldi $\mathrm{AC}$, et al. Detection of laccase, peroxidase and polyphenol oxidase on a single polyacrylamide gel electrophoresis. Anal Lett, 1997; 30:2211-20. 
Roder PV, Wu B, Liu Y, Han W. Pancreatic regulation of glucose homeostasis. Exp Mol Med, 2016; 48:e219.

Ronco C, Grammaticopoulos S, Rosner M, Decal M, Soni S, Lentini P, et al. Oliguria, creatinine and other biomarkers of acute kidney injury. Contrib Nephrol, 2010; 164:118-27.

Roy A, Geetha RV, Lakshmi T, Nallanayagam M. Edible fruits nature's gift for diabetic patients- a comprehensive review. Int J Pharm Sci Rev Res, 2011; 9:170-80.

Saxena AK, Srivastava P, Kale RK, Baquer NZ. Impaired antioxidant status in diabetic rat liver: effect of vanadate. Biochem Pharmacol, 1993; 45:539-42.

Schumann G, Klauke R. New IFCC reference procedures for the determination of catalytic activity concentrations of five enzymes in serum: preliminary upper reference limits obtained in hospitalized subjects. Clinica Chim Acta, 2003; 327:69-79.

Shanmugasundaram ERB, Gopinath KL, Shanmugasundaram $\mathrm{KR}$, Rajendran VM. Possible regeneration of the islets of langerhans in streptozotocindiabetic Rats given Gymnemasylvestre leaf extracts. J Ethnopharmocol, 1990; 30:265-79.

Sheweita SA, Mashaly S, Newairy AA, Abdou HM, Eweda SM. Changes in oxidative stress and antioxidant enzyme activities in streptozotocin-induced diabetes mellitus in rats: role of Alhagim aurorum extracts. Oxidative Med Cell Longev, 2016;2016:5264064. doi: 10.1155/2016/5264064.

Siciliano MJ, Shaw CR. Separation and visualization of enzymes on gels. In: Smith I (ed.). Chromatographic and electrophoretic techniques, Vol. 2, Zone Electrophoresis, Heinemann, London, UK, p 185, 1976.

Singleton VL, Rossi JA. Colorimetry of total phenolics with phosphomolybdicphosphotungstic acid reagents. Am J Enol Vitic, 1965; $16: 144-58$.

Subramaniam HN, Chaubal KA. Evaluation of intracellular lipids by standardized staining with a Sudan black B fraction. J Biochem Bioph Meth, 1990; 21:9-16.

Surya S, Salam AD, Tomy DV, Carla B, Kumar RA, Sunil C. Diabetes mellitus and medicinal plants-a review. Asian Pac J Trop Dis, 2014; 4:337-47.

Teoh SL, Latiff AA, Das S. A histological study of the structural changes in the liver of streptozotocin-induced diabetic rats treated with or without Momordicacharantia (bitter gourd). Clin Ter, 2009; 160:283-6.
Udia PM, Takem LP, Ufot UF, Antai AB, Owu DU. Insulin and alpha amylase levels in alloxan-induced diabetic rats and the effect of Rothmanniahispida (K. Schum) Fagerl leaf extract. J Phytopharmacol, 2016; 5:1-5.

Vivek KS. Streptozotocin: an experimental tool in diabetes and alzheimer's disease (A- Review). Int J Pharma Res Dev, 2010; 2:1-7.

Youssef AM, Abdel-Aziz MS, El-Sayed MS. Chitosan nanocomposite films based on Ag-NP and Au-NP biosynthesis by Bacillus subtilis as packaging material. Int J Biol Macromol, 2014; 69:185-91.

Youssef AM, El-Sayed SM. Bionanocomposites materials for food packaging applications: concepts and future outlook. Carbohydr Polym, 2018; 193:19-27.

Zafar M, Naeem-Ul-Hassan Naqvi S, Ahmed M, Kaimkhani ZA. Altered liver morphology and enzymes in streptozotocin induced diabetic rats. Int J Morphol, 2009; 27:719-25.

Zeindl-Eberhart E, Klugbauer S, Dimitrijevic N, Jungblut PR, Lamer S, Rabes HM. Proteome analysis of rat hepatomas: carcinogendependent tumor-associated protein variants. Electrophoresis, 2001; 22:3009-18.

Zhang Y, Wu L, Ma Z, Cheng J, Liu J. Anti-Diabetic, antioxidant and anti-hyperlipidemic activities of flavonoids from Corn silk on STZ-induced diabetic mice. Molecules, 2016; 21:7.

Zhao P, Li N, Astruc D. State of the art in gold nanoparticle synthesis. Coord Chem Rev, 2013; 257:638-65.

How to cite this article:

Abdel-Halim AH, Azeem Fyiad AA, Aboulthana WM, El-Sammad NM, Youssef AM, Ali MM. Assessment of the anti-diabetic effect of Bauhinia variegata gold nano-extract against streptozotocin induced diabetes mellitus in rats. J Appl Pharm Sci, 2020; 10(05):077-091. 